\title{
Macromolecular Structure Controlling Micro Mechanical Properties of Vitrinite and Inertinite in Tectonically Deformed Coals-A Case Study in Fengfeng Coal Mine of Taihangshan Fault Zone (North China)
}

\author{
Anmin Wang ${ }^{1,2, *}$, Daiyong Cao ${ }^{1}$, Yingchun Wei ${ }^{1}$ (D) and Zhifei Liu ${ }^{1}$ \\ 1 Department of Energy Geology, College of Geoscience \& Surveying Engineering, China University of \\ Mining \& Technology, Beijing 100083, China; cdy@cumtb.edu.cn (D.C.); wyc@cumtb.edu.cn (Y.W.); \\ BQT1700201024@student.cumtb.edu.cn (Z.L.) \\ 2 Shandong Key Laboratory of Depositional Mineralization \& Sedimentary Mineral, \\ Shandong University of Science and Technology, Qingdao 266510, China \\ * Correspondence: wamcumtb@163.com
}

Received: 13 November 2020; Accepted: 10 December 2020; Published: 15 December 2020

\begin{abstract}
In order to study the evolution of the mechanical properties and macromolecular structures in different macerals of tectonically deformed coal (TDC), vitrinite and inertinite samples were handpicked from six block TDCs in the same coal seam with an increasing deformation degree (unaltered, cataclastic, porphyroclast, scaly and powdery coal). The micro mechanical properties were tested by the nanoindentation experiment and the macromolecular structures were measured using ${ }^{13} \mathrm{C}$ nuclear magnetic resonance (NMR) and Fourier transform infrared spectroscopy (FTIR). The results show that the range of hardness and elastic modulus of inertinite is $0.373-1.517 \mathrm{GPa}$ and 4.339-12.158 GPa, respectively, which is significantly higher than that of vitrinite with values of 0.278-0.456 GPa and 4.857-7.810 GPa, respectively. From unaltered coal to powdery coal, the hardness of vitrinite and inertinite gradually decreases, with the difference between these macerals becomes smaller and the elastic modulus of vitrinite shows an increasing trend, while that of inertinite was more variable. Both the NMR and FITR results reveal that the macromolecular structure of inertinite has similar structural transitions as vitrinite. As the degree of deformation increases, the aliphatic side chains become shorter and the aromaticity is increasing. Macromolecular alterations caused by tectonic stress is expected to produce defects in the TDCs, therefore there should be more interspacing among the macromolecular groups for the extrusion of macromolecules caused by the indenter of the nanoindentation experiment, thereby reducing the hardness. The elastic modulus of coal is believed to be related to intermolecular forces, which are positively correlated to the dipole moment. By calculating the dipole moments of the typical aromatic molecular structures with aliphatic side chains, the detachment of the aliphatic side chains and the growth of benzene rings can both increase the dipole moment, which can promote elastic modulus. In addition, the increasing number of benzene rings can create more $\pi-\pi$ bonds between the molecules, which can lead to an increase in the intermolecular forces, further increasing the elastic modulus.
\end{abstract}

Keywords: tectonically deformed coal; vitrinite; inertinite; mechanical property; macromolecular structure

\section{Introduction}

The physical and chemical properties of tectonically deformed coal (TDC) are significantly different from those of unaltered coal [1]. Coal basins in China have generally experienced intensive tectonic 
movements [2,3]; therefore, TDCs are widespread, hindering the safe and effective exploitation of coal resources and coalbed methane [4-7]. Therefore, TDC has been studied extensively [8-10].

The traditional identification of the deformation degree of TDC is usually described qualitatively [1,11-13], because TDC is extremely soft and fragile. Thus, traditional testing methods of mechanical properties, such as triaxial or uniaxial mechanics, are not suitable for TDC, which can only be identified by macroscopic characteristics. TDC can be classified in different types with increasing deformation, such as cataclastic, porphyroclast, scaly, powdery, heterogeneous structure and mylonitic coal [14]. Godyńand and Kožušníková [15] studied the microhardness of TDC using the Vickers hardness test in Silesian Coal Basin, Poland and found the lowest values in cataclastic coal and the highest values in unalerted coal, which was a valuable discovery for TDC research. Therefore, there should be more quantitative descriptions for studies of TDC with different degrees of deformation.

For many years, the TDC samples were tested as a whole to analyze the changes in the physical and chemical structures [11,16]; however, few studies have measured the vitrinite and inertinite components separately, which have different physical and chemical characteristics [17-19]. Therefore, the deformation modes of vitrinite and inertinite vary considerably under the action of tectonic stress, thus, the physical and chemical properties of vitrinite and inertinite consequentially would undergo distinct changes. More and more researchers have noted that the coal maceral has influenced the mechanics of the coal. Pan et al. [20] revealed that the coal strength and Young's modulus are strongly related to coal rank and composition by comparing coals of different vitrinite reflectances and compositions. Hou et al. [21] determined that the hardness and elastic modulus are in the order of exinite < vitrinite < inertinite by employing depth-sensing nanoindentation. Kožušníková [22] revealed that the Vickers microhardness and elastic modulus of coal sample with higher coalification were lower than of coal sample with lower coalification and also, Godyńand et al. [23] found that micro-hardness value decreases with metamorphism degree using Vickers hardness test in Silesian Coal Basin, Poland. Fender et al. [24] suggested that thermally immature liptinite macerals have a lower modal modulus than the inertinites and the modal Young's modulus of all macerals increases with maturity, based on atomic force microscopy. Therefore, the mechanical properties of each maceral in coal are different, so the study of the mechanical evolution of different macerals has important scientific significance for improving the understanding of TDC.

The macromolecular evolution of TDC has gained great interest recently. Ju et al. [25] found that with the increasing degree of coal deformation, the hydrogen-enriched degree and oxygen-enriched degree decrease, while the degree of ring condensation increases. Cao et al. [8] demonstrated that tectonic stress affects the chemical structure of the coal through stress degradation and stress polycondensation; stress degradation is a process in which some chemical bonds of low activation energy are broken up under tectonic stress and the stress polycondensation indicates that the condensed aromatic nuclei tend to be arranged in parallel under tectonic stress. Song et al. [26] revealed that ductile deformation can promote the loss of aliphatic carbons and the degree of macromolecular alignment, while brittle deformation promoted transitions in the aliphatic structure. Liu and Jiang [13] thought that shear tectonic stress caused more stacked aromatic layers and a lower interlayer space. Therefore, there are multiple viewpoints; however, there has been little discussion regarding the macromolecular evolution of a single maceral in TDC.

There are at least three unresolved challenges: (1) a quantitative description of TDC classification; (2) the variations in the evolution of the mechanical properties of vitrinite and inertinite in TDC; and (3) how inertinite reacts to tectonic stress.

In this study, TDC samples with different degrees of deformation were collected from the same coal seam (No. 2 coal seam) in the Fengfeng coal mine of the Taihangshan fault zone, North China and the vitrinite and inertinite were separated by hand. The mechanical properties of vitrinite and inertinite with different degrees of deformation can be quantitatively described using nanoindentation. In addition, ${ }^{13} \mathrm{C}$ nuclear magnetic resonance (NMR) spectroscopy and Fourier transform infrared spectroscopy (FTIR) were employed to obtain the macromolecular structural evolution of the vitrinite 
and inertinite. Finally, the controlling effect of the macromolecular structural evolution on the changes in the mechanical properties are discussed.

\section{Geological Background}

The Fengfeng coal mine area is located in Taihangshan fault zone [3], North China, belonging to northern China coal occurrence area (Figure 1). The coal-bearing strata in the Fengfeng mining area is the Late Paleozoic Carboniferous-Permian with the No. 2 coal seam of Shanxi Formation being the mineable coal seam in the whole area and the coal-bearing strata are unconformable contacted with the underlying Ordovician limestone strata. In the western part of the Fengfeng mining area, there are magmatic rocks developed in the Late Jurassic period. Most of the magmatic rocks are ultrabasic, basic, neutral and partial alkaline rocks [27]. The Fengfeng mining area has undergone strong deformation since the Neogene and mainly developed NE-SW structural lines [27], including folds and faults, which also made the coal seam more severely deformed. These strongly deformed structures have seriously affected the exploration and development of coalbed methane in the Fengfeng mining area [28], as well as the safety production of coal mines.

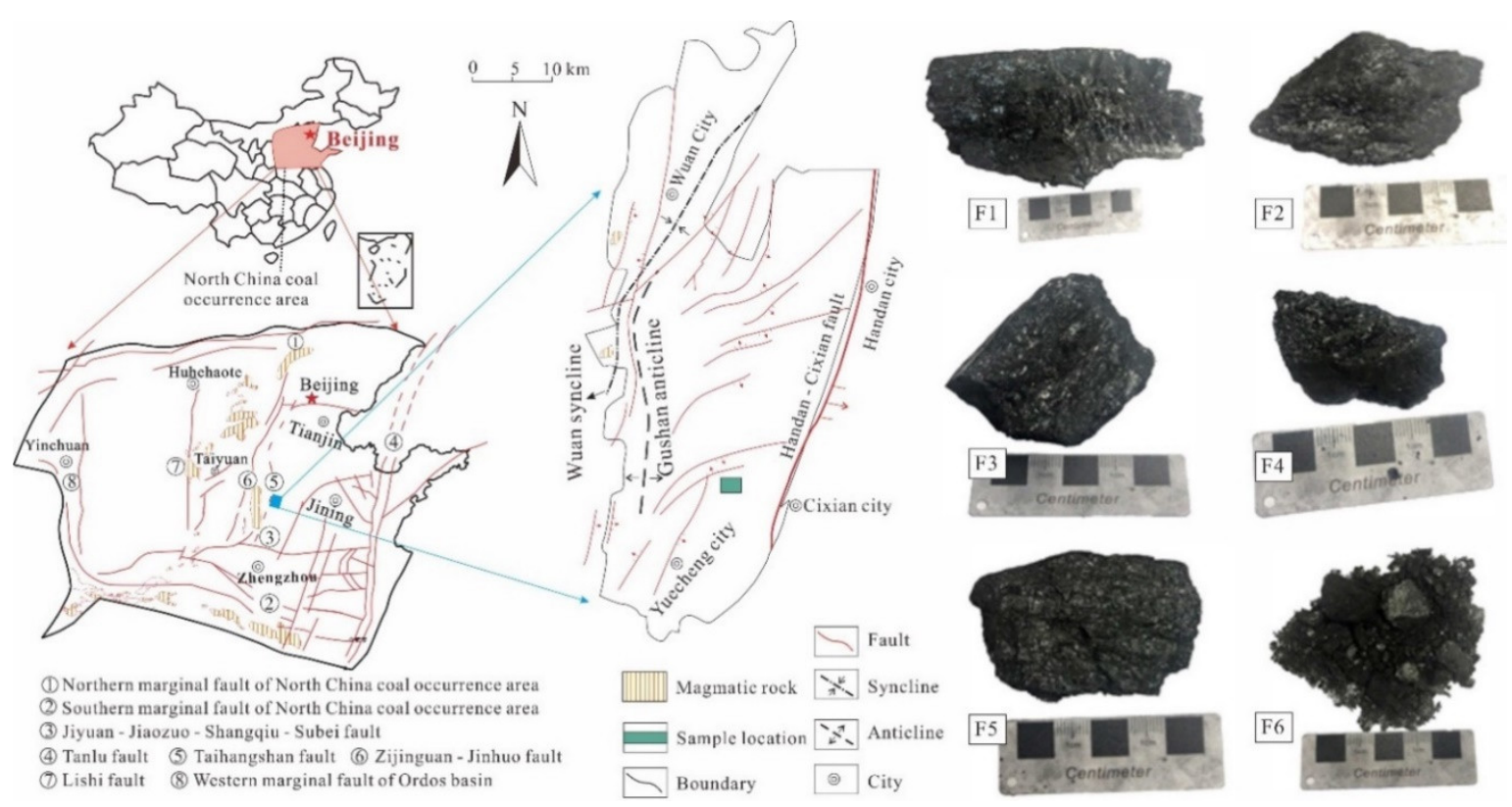

Figure 1. Geological structure of Fengfeng coal mine area with tectonically deformed coal (TDC) samples.

\section{Samples and Methods}

\subsection{Sample Preparation}

According to the classification of TDCs by Cao et al. [14] a total of 6 TDC samples, numbered F1-6, including five types of TDCs: unaltered, cataclastic, porphyroclast, scaly and powdery coal (Figure 1, Table 1), were collected from the No. 2 coal seam of Fengfeng coal mine of Taihangshan fault zone, North China, to ensure that the coal rank and maceral composition of all the samples were the same. The average vitrinite reflectance $\left(R_{\mathrm{o}}\right)$ of the No. 2 coal seam was $0.99 \%$ with a mean moisture content of $0.54 \%$, mean ash yield of $11.08 \%$ and mean volatile matter yield of $31.35 \%$. Vitrinite and inertinite were hand sorted from the vitrain and fusain in the collected samples, respectively, that is, coal samples were crushed into small particles in size and were put on a white paper under a lamp and vitrain particles glistened but fusain particles remained black. So, vitrain particles and fusain particles were separated with tweezers. Each sample was stripped into two samples, viz. vitrinite (-V) and inertinite (-I), providing a total of 12 samples (Table 1). Each stripped sample was identified by optical 
microscopy to ensure the correctness of the sample components until the corresponding component of each sample reached more than $90 \%$.

Table 1. Sample information.

\begin{tabular}{cccccc}
\hline \multirow{2}{*}{ Sample } & \multirow{2}{*}{ Coal Type } & \multicolumn{3}{c}{ Petrographic Analysis (\%) } \\
\cline { 4 - 6 } & & & Vitrinite & Inertinite & Other Groups \\
\hline \multirow{2}{*}{ F1 } & F1-V (Vitrinite) & \multirow{2}{*}{ Unaltered } & 93.50 & 2.10 & 4.40 \\
& F1-I (Inertinite) & & 1.80 & 91.60 & 6.60 \\
F2 & F2-V (Vitrinite) & \multirow{2}{*}{ Cataclastic } & 95.10 & 2.30 & 2.60 \\
& F2-I (Inertinite) & & 4.60 & 90.60 & 4.80 \\
F3 & F3-V (Vitrinite) & \multirow{2}{*}{ Porphyroclast } & 94.80 & 3.30 & 1.90 \\
& F3-I (Inertinite) & & 3.40 & 92.60 & 4.00 \\
F4 & F4-V (Vitrinite) & \multirow{2}{*}{ Porphyroclast } & 93.80 & 5.10 & 1.10 \\
& F4-I (Inertinite) & & 3.20 & 94.70 & 2.10 \\
F5 & F5-V (Vitrinite) & \multirow{2}{*}{ Scaly } & 96.60 & 1.20 & 2.20 \\
& F5-I (Inertinite) & & 2.40 & 94.90 & 2.70 \\
F6 & F6-V (Vitrinite) & \multirow{2}{*}{ Powdery } & 94.30 & 2.80 & 2.90 \\
& F6-I (Inertinite) & & 3.50 & 95.30 & 1.20 \\
\hline
\end{tabular}

\subsection{Nanoindentation Experiment}

Nanoindentation is a technology to measure the mechanical properties of samples at microscale [29] and the indentation point can be observed and selected under a microscope with higher accuracy. As shown in Figure 2, an indenter is pressed into the coal sample, forming an indentation profile that matches the shape of the indenter. Under the maximum pressure load, the distance between the bottom of the indenter and the initial surface is the maximum depth $h_{\max }$, while the displacement between the bottom and sunken surface of the coal sample is the contact depth $h_{c}$. The coal surface will not return to its original position after unloading. At this time, the distance between the deepest point of the sunken surface and the initial surface is defined as $h_{f}$. The pressure-loading/unloading process of the experiment was recorded by a sensor and the load-displacement curve of the nanoindentation was obtained (Figure 3).

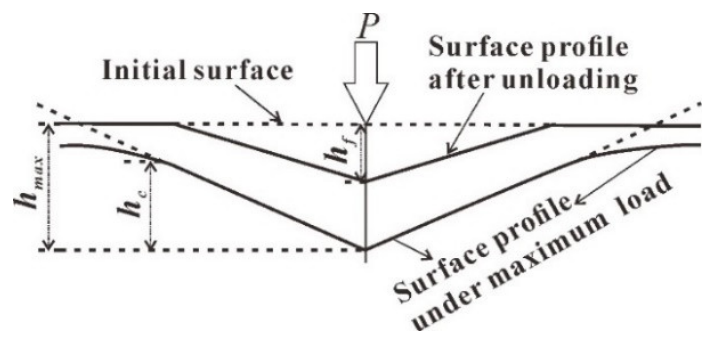

Figure 2. Schematic and parameters of nanoindentation. $h_{\max }$ is the maximum depth; $h_{\mathcal{c}}$ is the contact depth; $P$ is the loading pressure. 


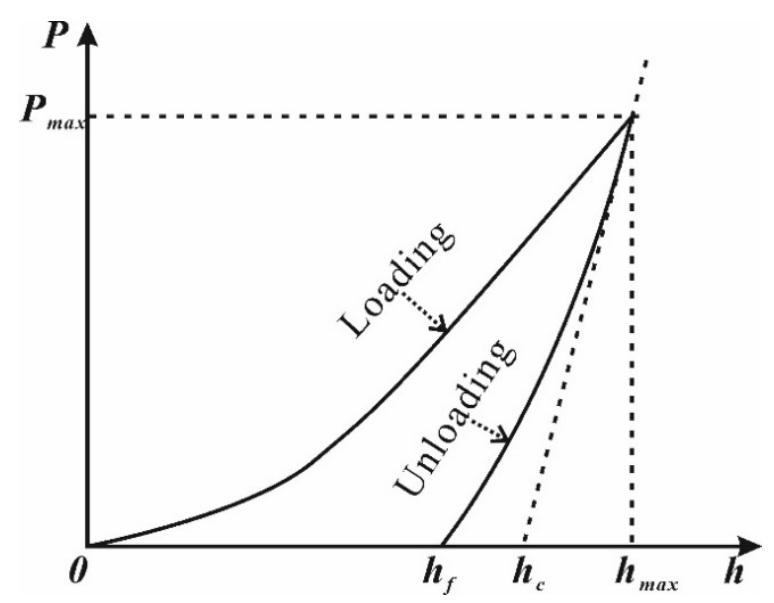

Figure 3. Typical load-displacement curve. $h_{f}$ is the distance between the deepest point of the sunken surface and the initial surface; $P_{\max }$ is the maximum loading pressure; $h$ is the depth.

Because the TDC is extremely soft, it must be conglutinated by epoxy resin so that the TDC can be tested, which is a common approach by many researchers because the "side-effect" of glue to the measurement results can be negligible [21]. The experimental equipment is a nanoindentation tester produced by Swiss CSM Instrument Co., Ltd, Peseux, Switzerland, with a minimum load of $25 \mu \mathrm{N}$, a maximum load of $350 \mathrm{mN}$ and a maximum indentation depth of $3100 \mu \mathrm{m}$, with a displacement resolution of $0.0004 \mathrm{~nm}$. In this study, the maximum pressure load was set to $100 \mathrm{mN}$ to ensure there could be indentation in the coal surface after unloading based on the laboratory' advice. Actually, the hardness and elastic modulus do not change with the maximum pressure which has been confirmed by Sun et al. [30], so the maximum pressure load setting could not affect the testing results as the hardness and elastic modulus are the only two results we want. The indentation points of the vitrinite samples were specified in telocollinite and those of the inertinite samples were placed in fusinite. Each sample was subjected to 5 nanoindentation experiments to ensure the accuracy of the experiment according to Sun et al.'s research [30].

Then, the hardness and modulus of the samples could be calculated using the Oliver-Pharr method [31]:

The unloading curve can be fitted with a power function as:

$$
P=\alpha\left(h-h_{f}\right)^{m},
$$

where $\alpha$ and $m$ are the fitted parameters and $h_{f}$ is the indentation depth after unloading, $\mathrm{nm}$.

The contact stiffness $S$ can be obtained by the differential computing of Equation (1) at the maximum load:

$$
S=\frac{d P}{d h_{\max }}=\alpha m\left(h_{\max }-h_{f}\right)^{m-1},
$$

where $h_{\max }$ is the maximum depth $(\mathrm{nm})$. The contact depth $h_{\mathcal{c}}(\mathrm{nm})$ can be calculated as:

$$
h_{c}=h_{\max }-\frac{\varepsilon P_{\max }}{S},
$$

where $P_{\max }$ is the maximum load, $\mu \mathrm{N}$, and $\varepsilon$ is a constant referring to the shape of the indenter. For the Berkovich indenter used in this experiment, the value is 0.75 . The contact area $A$ can be calculated by Equation (4):

$$
A=24.5 h_{c}^{2},
$$


Then, the hardness ( $H, \mathrm{GPa})$ of the samples can be obtained by Equation (5):

$$
H=\frac{P_{\max }}{A},
$$

The elastic modulus can be calculated using Equations (6) and (7):

$$
\begin{gathered}
\frac{1}{E_{r}}=\frac{1-v^{2}}{E}+\frac{1-v_{i}^{2}}{E_{i}}, \\
E_{r}=\frac{\sqrt{\pi}}{2 \beta} \frac{S}{\sqrt{A}},
\end{gathered}
$$

where $E$ is the elastic modulus (GPa). $v$ is Poisson's ratio, which is 0.3 for the coal in this study. $E_{i}$ and $v_{i}$ are the elastic modulus and Poisson's ratio of the indenter, respectively, for the Berkovich indenter in this experiment, $E_{i}=1141 \mathrm{GPa}$ and $v_{i}=0.07 . \beta$ is a constant related to the indenter's shape, for the Berkovich indenter, $\beta=1.034$.

\section{3. ${ }^{13} \mathrm{C}$ NMR Experiment}

Samples were crushed below 80 mesh and were demineralized by hydrochloric acid and hydrofluoric acid to exclude the mineral effect on the test results and the ${ }^{13} \mathrm{C}$ solid-state nuclear magnetic resonance experiment was carried out using the Agilent $600 \mathrm{M}$ equipment (Agilent Technologies Co. Ltd., Palo Alto, CA, USA). The instrument parameters were as follows: double-resonance probe head, $\mathrm{ZrO}_{2}$ rotor with outer diameter of $4 \mathrm{~mm}$ and magic angle spinning speed of $8 \mathrm{KHz}$. The experimental data were recorded by the probe on an Agilent DSX-300 (Agilent Technologies Co. Ltd., Palo Alto, CA, USA) spectrometer at ambient temperature. The radio frequency field strength of the ${ }^{13} \mathrm{C}$ was set to $600 \mathrm{MHz}$ and the cross-polarization contact time was $2 \mathrm{~ms}$.

\subsection{FTIR Experiment}

The samples were crushed to below 80 mesh and were demineralized by hydrochloric acid and hydrofluoric. After drying to remove the water, 1-2 mg of each sample powder was mixed with $200 \mathrm{mg}$ potassium bromide. After being tableted by a tablet machine, the samples were placed into infrared spectrometer chamber to be scanned with a spectral resolution of $4 \mathrm{~cm}^{-1}$ The Fourier transform infrared spectroscopy (FTIR) curves were obtained using a computer and were processed by the OMINC software. According to previous studies on the peak attribution of different infrared spectrum bands, the infrared spectrum curves were divided into different bands for further analysis, as shown in Table 2 shows [32,33].

Table 2. The band assignments for functional groups in coal Fourier transform infrared (FTIR) spectra $[32,33]$.

\begin{tabular}{cc}
\hline Band Position $\left.\mathbf{~ ( m ~}^{\mathbf{- 1}}\right)$ & Assignments \\
\hline $3600-3200$ & $-\mathrm{OH}$ stretching \\
$3000-2800$ & Aliphatic CH stretching \\
$1650-1520$ & Aromatic $\mathrm{C}=\mathrm{C}$ ring stretching \\
$1460-1350$ & Aliphatic $\mathrm{CH}_{2}$ and $\mathrm{CH}_{3}$ deformation \\
$1200-1000$ & $\mathrm{C}-\mathrm{O}-\mathrm{C}$ stretching \\
$900-700$ & Aromatic $\mathrm{C}-\mathrm{H}$ (out-plane bending modes) \\
\hline
\end{tabular}

The obtained infrared spectrum curves were analyzed by the curve-fitting method [13] and macromolecular structures can be characterized by the following parameters [34-37]:

1. $\mathrm{CH}_{2} / \mathrm{CH}_{3}=A\left(2940-2900 \mathrm{~cm}^{-1}\right) / A \quad\left(2940-3000 \mathrm{~cm}^{-1}\right)$, representing the length of aliphatic side-chains; 
2. $I=A\left(900-700 \mathrm{~cm}^{-1}\right) / A\left(3000-2800 \mathrm{~cm}^{-1}\right)$, representing the aromatic degree;

3. $D O C=A\left(900-700 \mathrm{~cm}^{-1}\right) / A\left(1600 \mathrm{~cm}^{-1}\right)$, representing the polycondensation degree of the aromatic rings;

4. $H_{a r} / H_{a l}=A\left(1650-1520 \mathrm{~cm}^{-1} / A\left(3000-2800 \mathrm{~cm}^{-1}\right)\right.$, representing the relative abundance of aromatic to aliphatic hydrogen.

\section{Results}

\subsection{Nanoindentation Experiment Results}

The nanoindentation pictures are shown in Figure 4. The vitrinite exhibits a conspicuous concave indentation after unloading, while the inertinite displays only a shallow indentation, indicating that inertinite has stronger resistance to pressure than vitrinite. For the vitrinite, the indentation depth increases from F1-I to F6-I, indicating the hardness decreases with the increasing deformation degree.
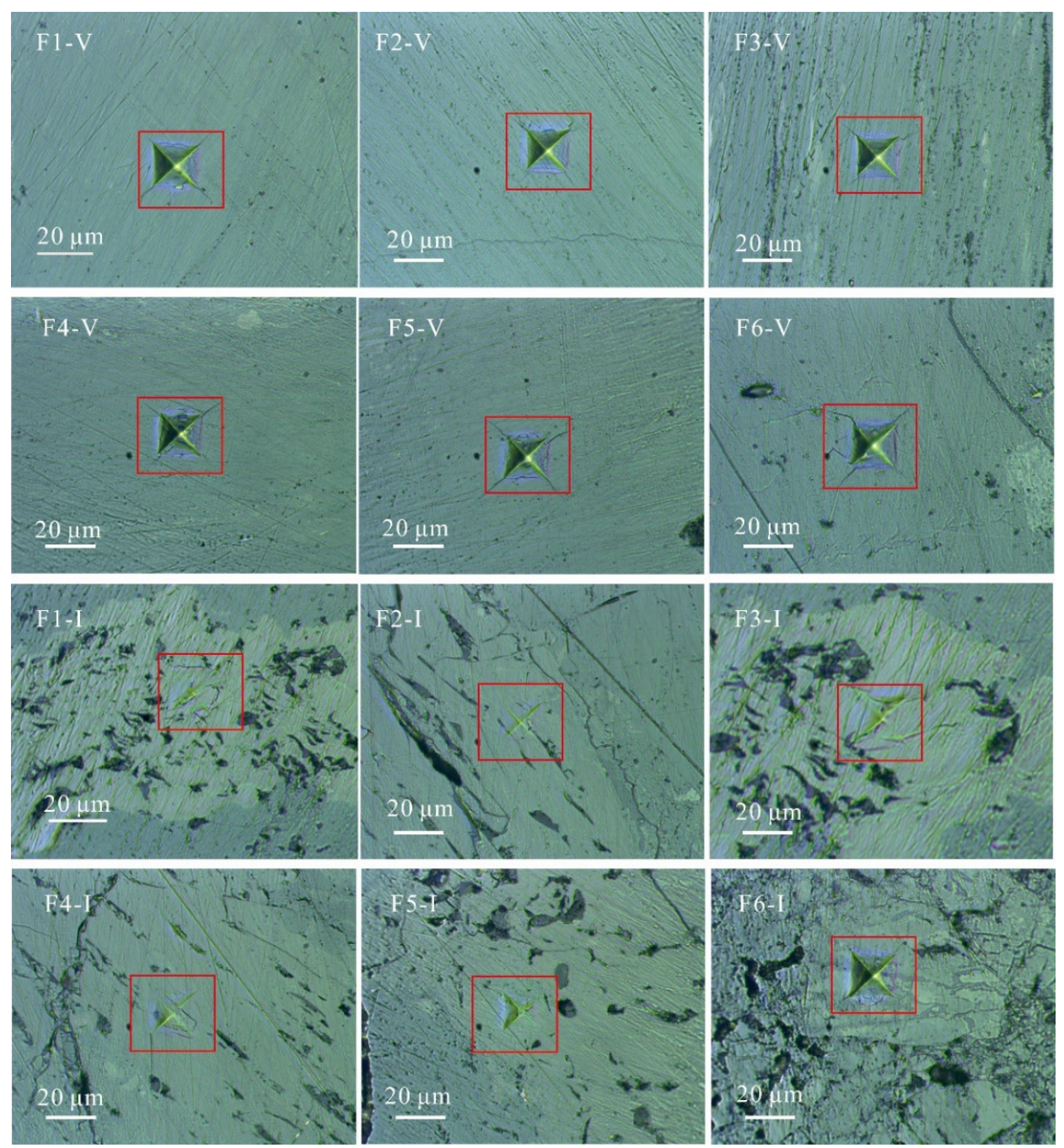

Figure 4. Typical nanoindentation image of each sample (the indentation is in the red box).

Comparing the $h_{\max }$ and $h_{f}$ of the vitrinite with those of the inertinite (Figure 5), the indentation depth of the inertinite is smaller than that of the vitrinite group. However, as the deformation degree of TDC increases, the $h_{\max }$ and $h_{f}$ of both vitrinite and inertinite increase, with the difference decreasing, indicating that with the increase of deformation degree, the resistance of both vitrinite and inertinite becomes weaker and the difference between the two becomes smaller. 


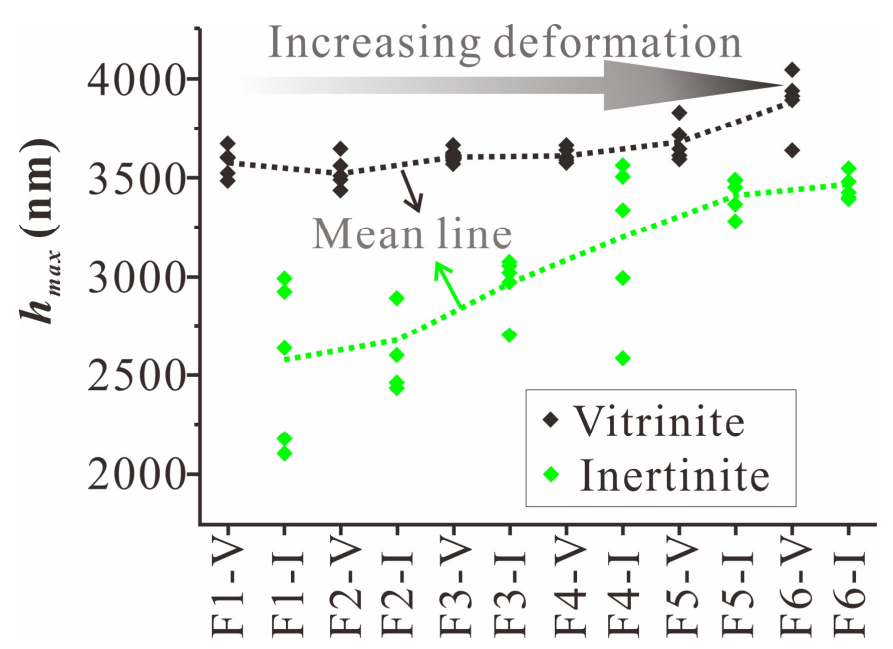

(a)

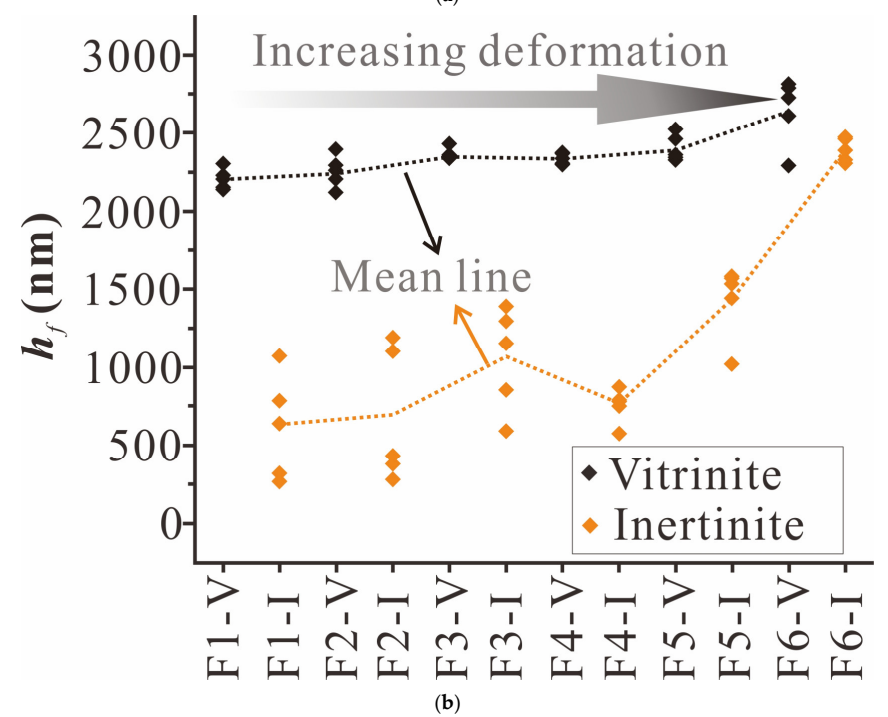

Figure 5. $h_{\max }$ and $h_{f}$ of tectonically deformed coal samples. (a) $h_{\max }$ of samples (b) $h_{f}$ of samples. $h_{\max }$ is the maximum depth; $h_{f}$ is the distance between the deepest point of the sunken surface and the initial surface.

The load-displacement curves obtained are shown in Figure 6. The displacement of vitrinite is noticeably greater than that of inertinite and the load-displacement curves of vitrinite are closer to each other, while those of inertinite are more scattered. From unaltered coal to powdery coal, the load-displacement curves of vitrinite and inertinite also become closer, indicating that as the deformation degree increases, the difference in the mechanical properties of vitrinite and inertinite diminishes. 

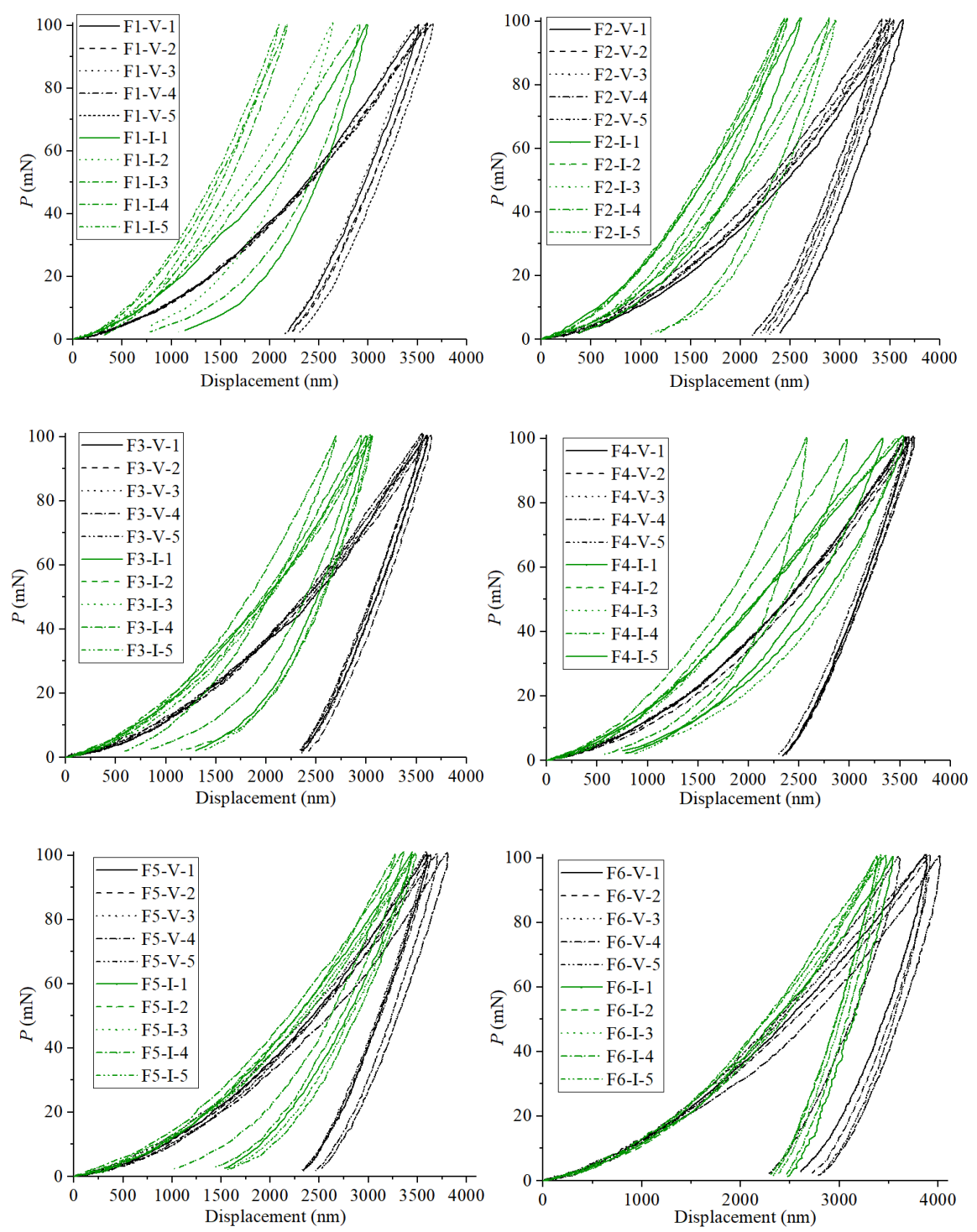

Figure 6. Load-displacement curves of samples (five measure points for each sample).

The calculated hardness and modulus are listed in Table 3. Overall, the $H$ of the inertinite is higher than that of the vitrinite. As the degree of deformation increases, the standard deviation of $E$ and $H$ of inertinite decreases from F1-I to F6-I, indicating that the hardness and elastic modulus of inertinite are more homogeneous and the hardness of both inertinite and vitrinite gradually decreases. The reduction in $H$ of the inertinite is significantly higher than that of the vitrinite with increasing deformation, so that the difference between the two lessens (Figure 7a). The elastic modulus $E$ of inertinite is also higher than that of vitrinite. As the degree of deformation is increased, the elastic modulus of the inertinite decreases and then increases, showing no obvious regularity but that of the vitrinite gradually increases (Figure $7 b$ ). 
Table 3. Calculation results of $E$ and $H$.

\begin{tabular}{|c|c|c|c|c|c|c|c|c|c|c|c|c|c|}
\hline & \multirow{2}{*}{ Sample } & \multicolumn{6}{|c|}{ Vitrinite } & \multicolumn{6}{|c|}{ Inertinite } \\
\hline & & F1-V & F2-V & F3-V & F4-V & F5-V & F6-V & F1-I & F2-I & F3-I & F4-I & F5-I & F6-I \\
\hline \multirow{7}{*}{$H(\mathrm{GPa})$} & Data: 1 & 0.443 & 0.402 & 0.404 & 0.414 & 0.390 & 0.308 & 0.572 & 0.695 & 0.574 & 0.542 & 0.486 & 0.373 \\
\hline & Data: 2 & 0.441 & 0.426 & 0.390 & 0.400 & 0.387 & 0.291 & 0.780 & 0.830 & 0.543 & 0.673 & 0.555 & 0.400 \\
\hline & Data: 3 & 0.456 & 0.417 & 0.402 & 0.414 & 0.399 & 0.283 & 0.612 & 0.623 & 0.544 & 0.450 & 0.454 & 0.413 \\
\hline & Data: 4 & 0.428 & 0.443 & 0.450 & 0.404 & 0.361 & 0.278 & 1.378 & 0.679 & 0.617 & 0.615 & 0.494 & 0.426 \\
\hline & Data: 5 & 0.409 & 0.446 & 0.422 & 0.402 & 0.367 & 0.378 & 1.517 & 0.841 & 0.871 & 0.481 & 0.446 & 0.429 \\
\hline & Mean & 0.435 & 0.427 & 0.414 & 0.407 & 0.381 & 0.308 & 0.972 & 0.734 & 0.630 & 0.552 & 0.487 & 0.408 \\
\hline & Standard deviation & 0.016 & 0.016 & 0.021 & 0.006 & 0.014 & 0.037 & 0.397 & 0.087 & 0.124 & 0.083 & 0.039 & 0.020 \\
\hline \multirow{7}{*}{$E(\mathrm{GPa})$} & Data: 1 & 5.108 & 5.227 & 5.261 & 5.261 & 5.494 & 6.124 & 7.347 & 7.588 & 6.932 & 4.839 & 4.830 & 6.794 \\
\hline & Data: 2 & 4.857 & 5.552 & 5.291 & 5.152 & 5.325 & 6.731 & 8.215 & 7.771 & 7.053 & 12.158 & 5.100 & 6.686 \\
\hline & Data: 3 & 5.180 & 5.383 & 5.267 & 5.309 & 5.520 & 7.810 & 7.384 & 6.770 & 7.252 & 5.021 & 5.295 & 6.845 \\
\hline & Data: 4 & 4.935 & 5.721 & 5.155 & 5.007 & 4.891 & 6.191 & 9.309 & 6.735 & 6.819 & 6.443 & 5.372 & 6.643 \\
\hline & Data: 5 & 4.884 & 5.383 & 5.340 & 5.529 & 5.337 & 5.674 & 9.707 & 7.070 & 6.570 & 4.339 & 5.160 & 6.619 \\
\hline & Mean & 4.993 & 5.453 & 5.263 & 5.252 & 5.313 & 6.506 & 8.392 & 7.187 & 6.925 & 6.560 & 5.151 & 6.717 \\
\hline & Standard deviation & 0.128 & 0.169 & 0.061 & 0.173 & 0.226 & 0.733 & 0.971 & 0.423 & 0.228 & 2.885 & 0.187 & 0.088 \\
\hline
\end{tabular}

Note: Data 1 to 5 are the five measure points of each sample.

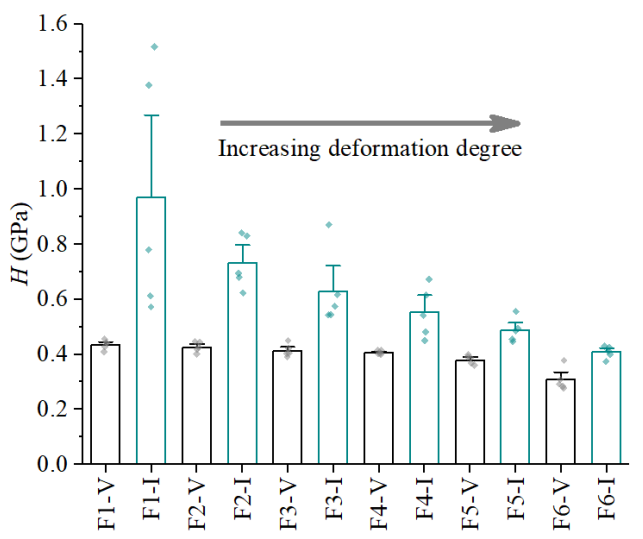

(a)

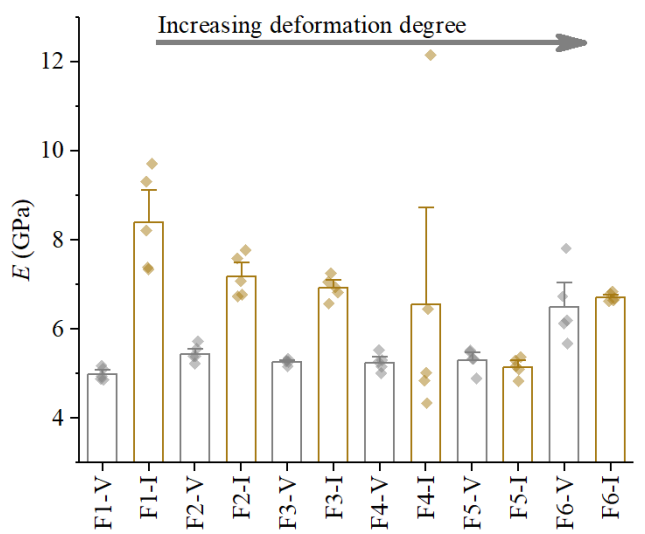

(b)

Figure 7. Distributions of $H$ and $E$ ( $H$ is the hardness; $E$ is the elastic modulus; (a) and (b) are the distributions of $H$ and $E$, respectively).

\subsection{NMR Experiment Results}

The NMR curves obtained are shown in Figure 8. According to previous studies, the NMR spectrum can be divided into three parts [38,39]: Aliphatic carbons (0-90 ppm), aromatic carbons (90-165 ppm) and carbonyl carbons or carboxyl carbons (165-240 ppm). As the degree of deformation increases, the aliphatic carbon peaks of both the vitrinite and inertinite gradually become flat, while the peak shapes of the aromatic carbon peaks are not significantly different, indicating that the deformation of TDC has a stronger influence on aliphatic carbon than aromatic carbon. 


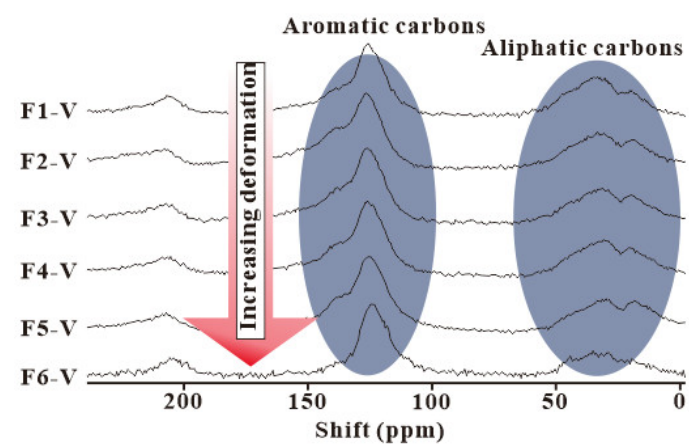

(a)

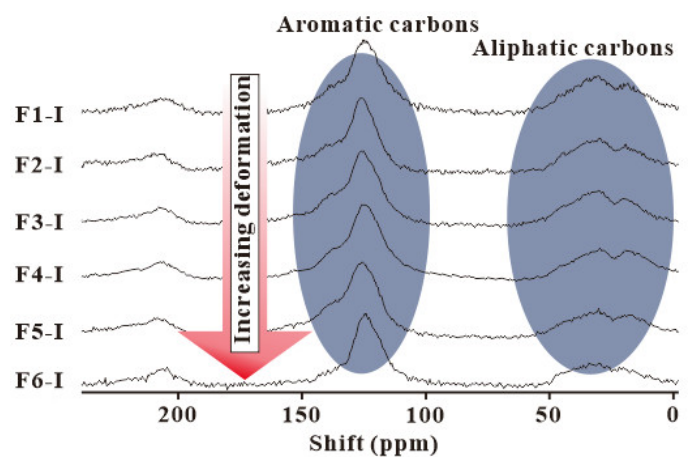

(b)

Figure 8. Nuclear magnetic resonance (NMR) spectra of vitrinite (a) and inertinite (b).

The NMR spectra of the samples were analyzed using the curve-fitting method (Figure 9). Based on the widely used values for the chemical shifts related to different functional groups of coal [40-42], $f_{a l}$ (aliphatic carbons, 0-90 ppm), $f_{a}$ (aromatic carbons, 90-165 ppm), $f_{a}{ }^{H}$ (protonated aromatic carbons, 100-129 ppm), $f_{a}^{B}$ (aromatic bridgehead carbons, 129-135 ppm), $f_{a}{ }^{S}$ (alkylation aromatic carbons, 135-150 ppm) and $f_{a}{ }^{P}$ (non-protonated aromatic carbon constituted by phenolic, 150-165 ppm) have been calculated. In addition, the $X_{B P}$ (the ratio of aromatic bridge carbon to aromatic peripheral carbon), which is an indicator of the basic structural unit (BSU) size [9], was calculated following $X_{B P}=f_{a}{ }^{B} /\left(f_{a}{ }^{H}+f_{a}{ }^{P}+f_{a}{ }^{S}\right)$. In this study, $f_{a} / f_{a l}$ was also calculated to reveal the degree of enrichment of aromatic carbons to aliphatic carbons.

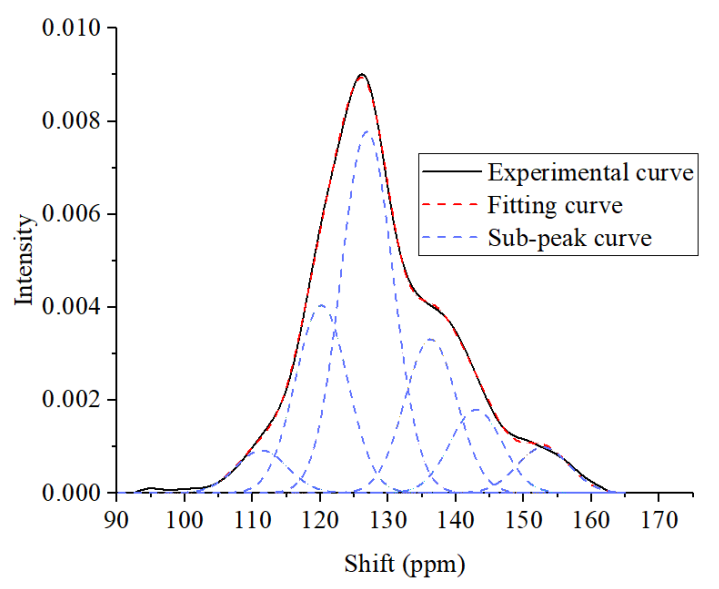

Figure 9. Curve-fitting method (Taking Sample F1-V as an example).

The calculated results are shown in Figure 10. The deformation degree of the TDC increases from samples F1 to F6, with evident changes as the deformation degree is increased, indicating that tectonic stress can induce the macromolecular structural evolution of coal. In particular, the macromolecular structure of inertinite also changes with deformation degree, implying that inertinite is not inert to tectonic stress. Each NMR parameter of vitrinite and inertinite changes with the deformation degree of the coal. The $f_{a l}$ of vitrinite and inertinite decreases with the increasing deformation degree (Figure 10a) so it can be inferred that tectonic stress can reduce aliphatic carbons. Compared with $f_{a l}$, the $f_{a}$ of vitrinite and inertinite gradually increases (Figure 10b), suggesting that the aliphatic carbons have a process of transforming into aromatic carbons that can also be triggered by tectonic stress. The $f_{a l}$ decreases and $f_{a}$ increases, so the $f_{a} / f_{a l}$ consequentially increases with the deformation degree (Figure 10g), leading to an increase in the relative aromatic carbons, which is similar to the findings of Song et al. [26]. The $f_{a}{ }^{H}, f_{a}{ }^{B}, f_{a}{ }^{S}$ and $f_{a}{ }^{P}$ show no obvious regularities with change in the deformation degree (Figure 10c-f). In addition, $X_{B P}$ also shows a negative relationship with the deformation degree 
of the TDC (Figure 10h), indicating that tectonic stress had destroyed the original basic structural unit (BSU) in the coal, decreasing the size of the BSU with the deformation degree.

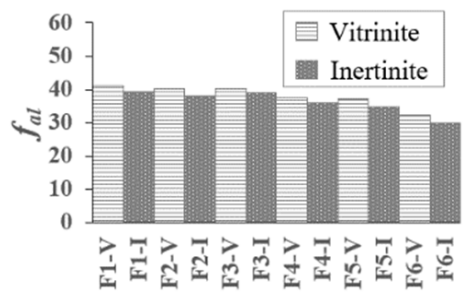

(a)

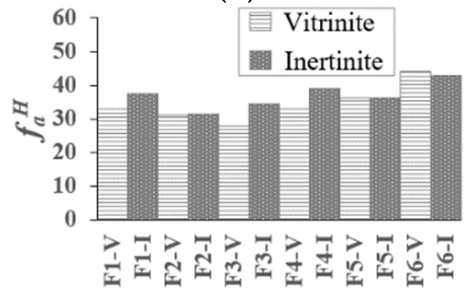

(c)

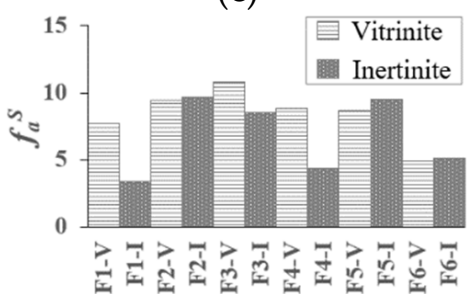

(e)

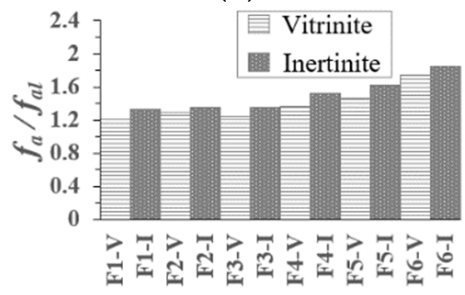

(g)

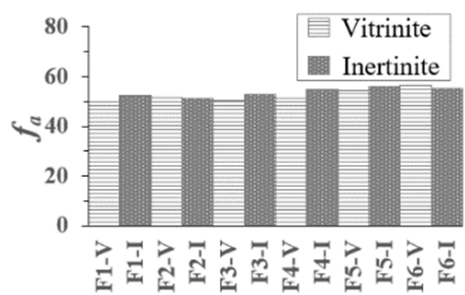

(b)

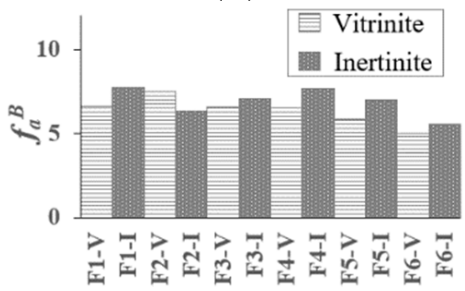

(d)

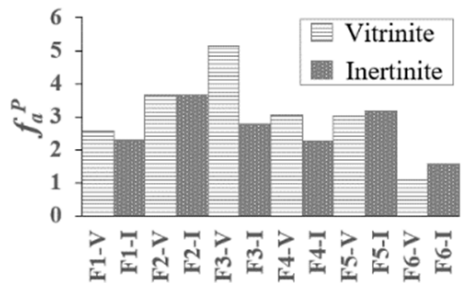

(f)

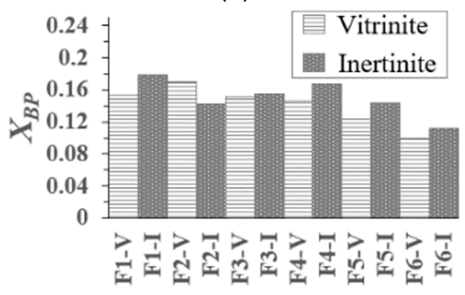

(h)

Figure 10. NMR structure parameters of samples $\left((\mathbf{a}-\mathbf{h})\right.$ are the distributions of $f_{a l}, f_{a}, f_{a}{ }^{H}, f_{a}{ }^{B}, f_{a}{ }^{S}, f_{a}{ }^{P}$, $f_{a} / f_{a l}$, and $X_{B P}$, respectively). $f_{a l}$ is aliphatic carbons; $f_{a}$ is aromatic carbons; $f_{a}{ }^{H}$ is protonated aromatic carbons; $f_{a}{ }^{B}$ is aromatic bridgehead carbons; $f_{a}{ }^{S}$ is alkylation aromatic carbons; $f_{a}{ }^{P}$ is non-protonated aromatic carbon constituted by phenolic; and $X_{B P}$ is the ratio of aromatic bridge carbon to aromatic peripheral carbon.

\subsection{FTIR Experiment Results}

The infrared spectrum curves of vitrinite and inertinite are shown in Figure 11. There are obvious changes in the curves along with the different deformation degree, once again proving that under the action of tectonic stress, the inertinite is not inert. For both vitrinite and inertinite, the variation degree of aliphatic $\mathrm{C}-\mathrm{H}$ is noticeably stronger than that of aromatic $\mathrm{C}=\mathrm{C}$, in agreement with the NMR data. 


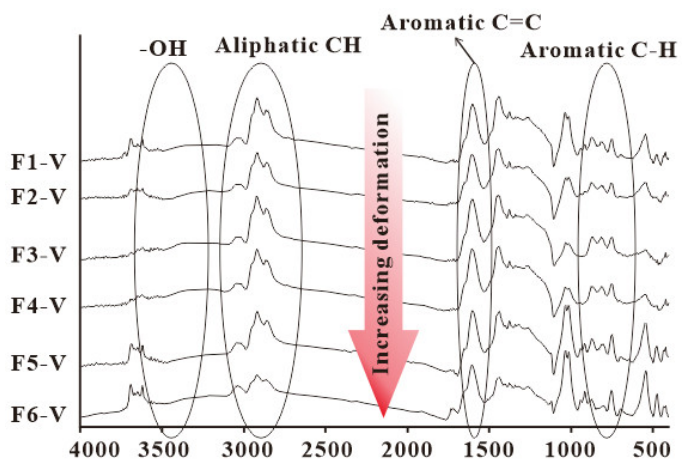

(a)

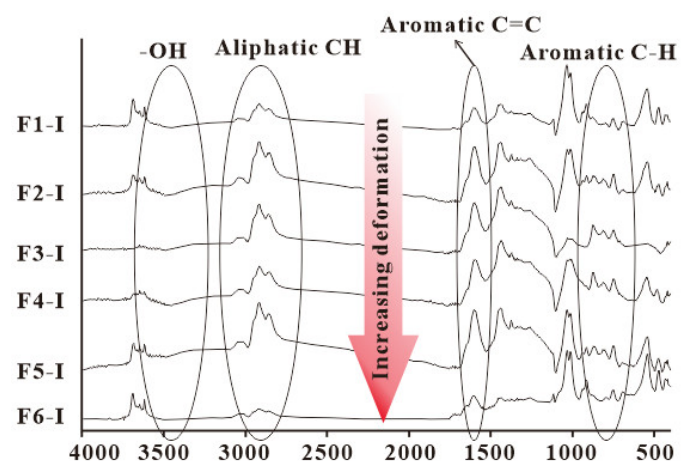

(b)

Figure 11. FTIR spectrum of vitrinite (a) and inertinite (b).

The calculated macromolecular parameters are shown in Figure 12. (1) The $\mathrm{CH}_{2} / \mathrm{CH}_{3}$ of vitrinite and inertinite decreases from Sample F1 to F6 (Figure 12a), indicating that the aliphatic side-chains gradually detached with the increasing deformation degree of the TDC, which is in agreement with the results of the NMR. (2) The aromatic degree (I) of vitrinite gradually fluctuates upward from Sample F1 to F6 (Figure 12b), suggesting that the aromatic degree is positively correlated with the deformation. (3) The polycondensation degree of the aromatic rings (DOC) of vitrinite and inertinite does not show any obvious relation with the deformation degree (Figure 12c), indicating that the polycondensation degree of aromatic rings does not increase with the increasing deformation. (4) The relative abundance of aromatic to aliphatic hydrogen $\left(H_{a r} / H_{a l}\right)$ of vitrinite and inertinite increases from Sample F1 to F6 (Figure 12d), implying that the aliphatic carbon decreases but aromatic carbon increases, which coincide with the NMR results in Section 4.2.

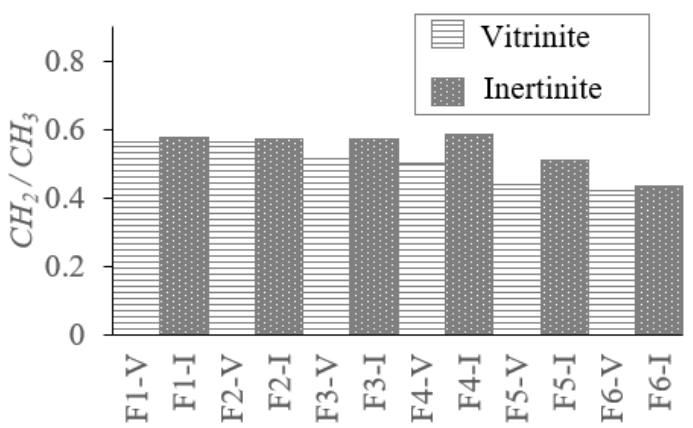

(a)

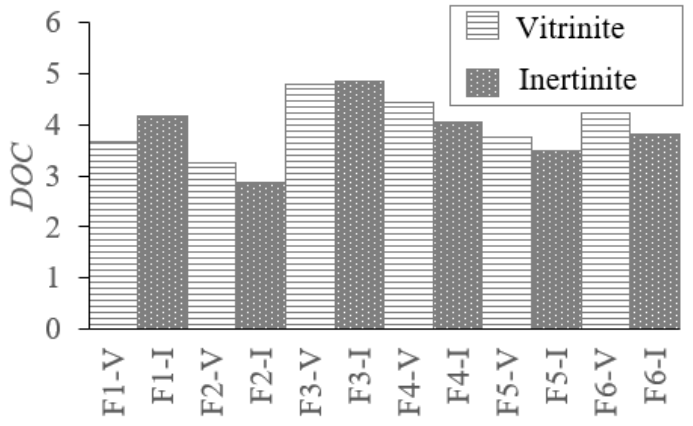

(c)

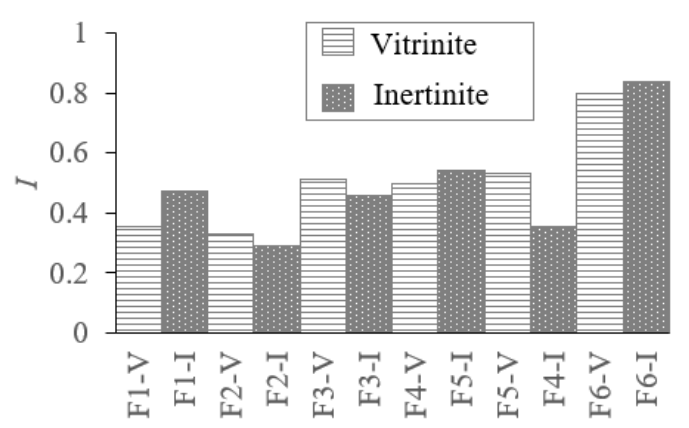

(b)

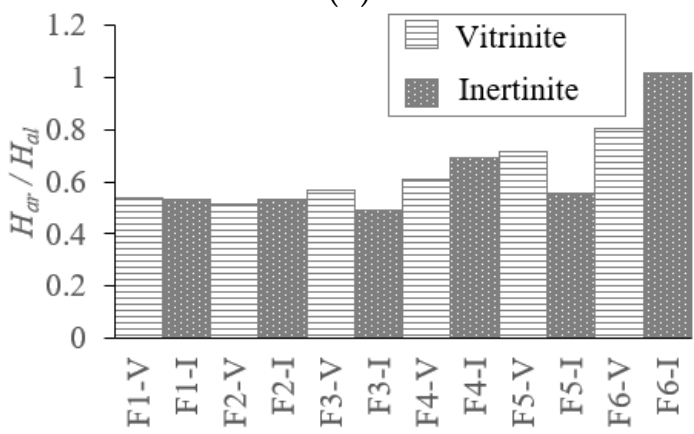

(d)

Figure 12. FTIR structure parameters of samples ( (a-d), are the distributions of $\mathrm{CH}_{2} / \mathrm{CH}_{3}, \mathrm{I}, \mathrm{DOC}$, and $\mathrm{H}_{a r} / \mathrm{H}_{a l}$, respectively). $\mathrm{CH}_{2} / \mathrm{CH}_{3}$ represents the length of aliphatic side-chains; $I$ represents the aromatic degree; $D O C$ represents the polycondensation degree of the aromatic rings; $H_{a r} / H_{a l}$ represents the relative abundance of aromatic to aliphatic hydrogen. 


\section{Discussion}

\subsection{Macromolecular Structure Controlling Effect on Mechanical Property of TDCs}

\subsubsection{Macromolecular Structure Effect on the Hardness (H) of TDC}

There are exponentially positive relationships between the $f_{a l}$ and mean $H$ values (Figure 13a) and exponentially negative correlations between the $f_{a}$ and $H$ (Figure 13b) of both vitrinite and inertinite, indicating that more aliphatic and aromatic carbons suggest a greater hardness of the TDC. The $f_{a}{ }^{H}$ decreases logarithmically with increasing $H$ (Figure 13c), while $f_{a}{ }^{B}$ increases logarithmically with increasing $H$ (Figure 13d), suggesting that increasing the protonated aromatic and decreasing aromatic bridgehead carbons could reduce the hardness of the TDC. There are exponentially positive correlations between $X_{B P}$ and $H$ and negative correlations between $f_{a} / f_{a l}$ and $H$, with a high correlation in vitrinite and low correlation in inertinite (Figure 13e-f), implying that a smaller BSU size and higher $f_{a} / f_{a l}$ ratio could reduce the hardness of the TDC. The $\mathrm{R}^{2}$ values of inertinite in Figure $14 \mathrm{c}, \mathrm{d}$ are relatively low, so the inferences above are more suitable for vitrinite.

The macromolecular evolution of both vitrinite and inertinite also can be described by the increasing deformation degree of the TDC. The tectonic stress leads to a decrease in the aliphatic carbons and an increase in $f_{a}$ and the ratio of $f_{a} / f_{a l}$. The tectonic stress also decreases the $X_{B P}$ and all the changes in the macromolecular structure could reduce the hardness of the TDC. In addition, this is clear evidence that, in addition to thermal metamorphism, tectonic stress can change the macromolecular structure of coal.

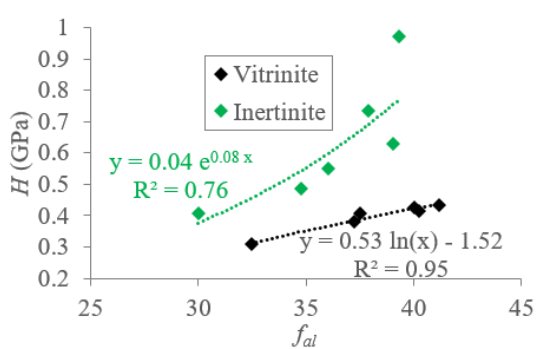

(a)

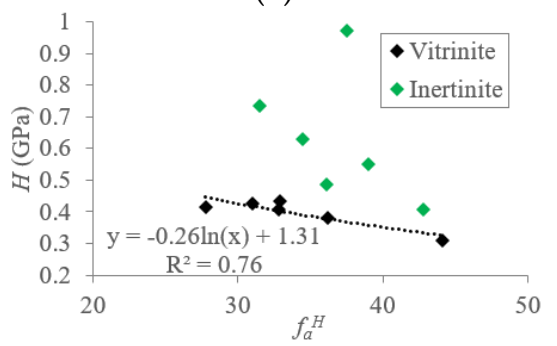

(c)

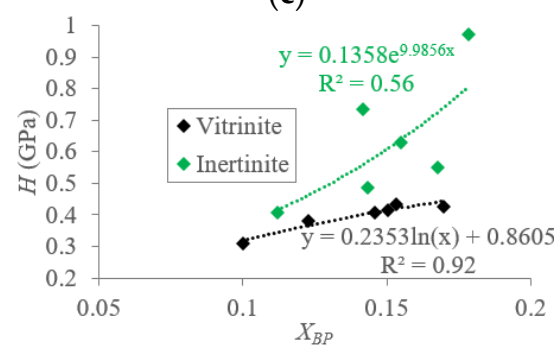

(e)

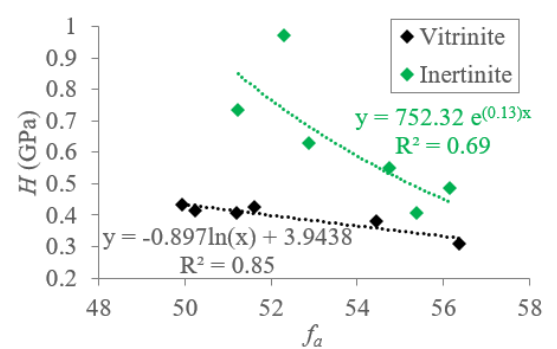

(b)

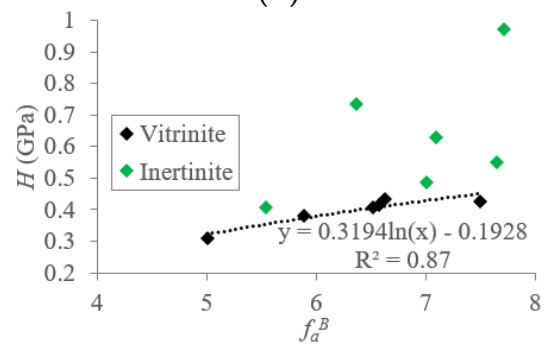

(d)

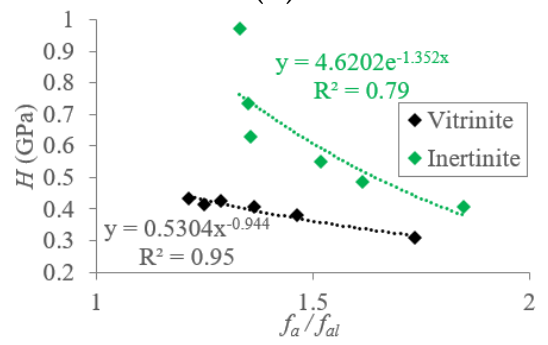

(f)

Figure 13. Relationships between NMR parameters $\left((\mathbf{a}-\mathbf{f})\right.$ are the $f_{a l}, f_{a}, f_{a}{ }^{H}, f_{a}{ }^{B}, X_{B P}$, and $f_{a} / f_{a l}$, respectively) and $H$. (Note: Here, $H$ is the mean value for each sample). 
There are exponentially positive correlations between $\mathrm{CH}_{2} / \mathrm{CH}_{3}$ and $\mathrm{H}$ and between $\mathrm{I}$ and $\mathrm{H}$ (Figure 14a,b), suggesting that with more aliphatic side chains and a higher aromatic degree, the $H$ of the TDC is higher. The hardness does not show any correlations with DOC (Figure 14c) but is exponentially correlated with $H_{a r} / H_{a l}$, with $\mathrm{R}^{2}$ values of 0.86 (vitrinite) and 0.59 (inertinite) (Figure $14 \mathrm{~d}$ ), indicating that the increase in the relative abundance of aromatic to aliphatic hydrogen will reduce the hardness of the TDC.

Therefore, the process in which the macromolecular structure of vitrinite and inertinite of TDC changes with the increase in deformation can be described as follows: As the degree of deformation increases, the aliphatic side chains gradually detach and the aromatic degree gradually increases, representing that the relative content of aromatic carbons increase and the aliphatic carbons decrease, reducing the hardness of the TDC.

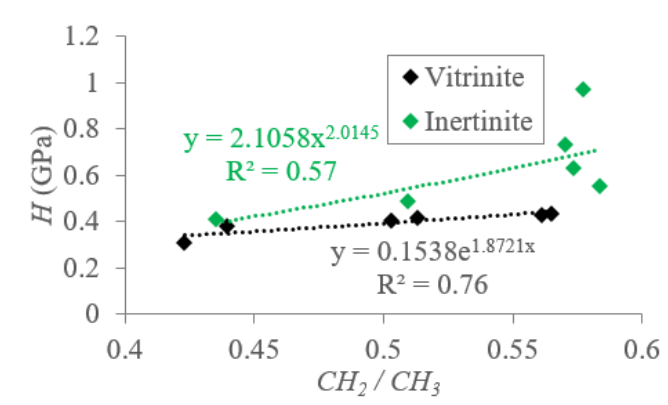

(a)

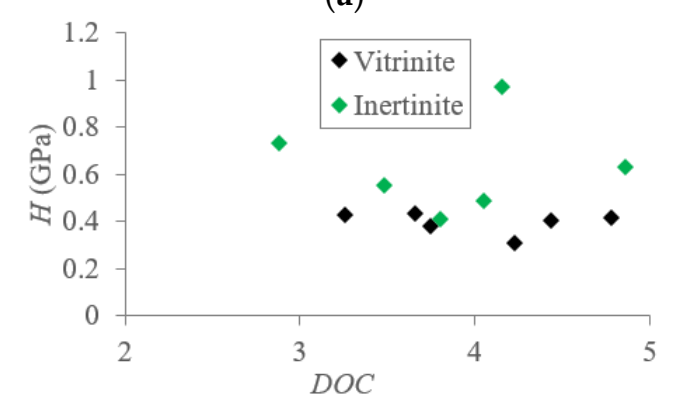

(c)

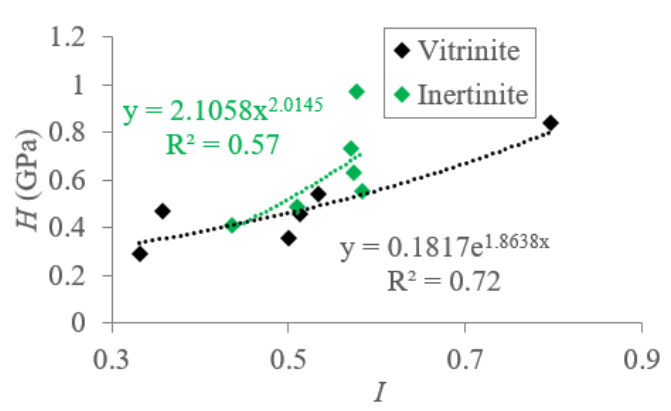

(b)

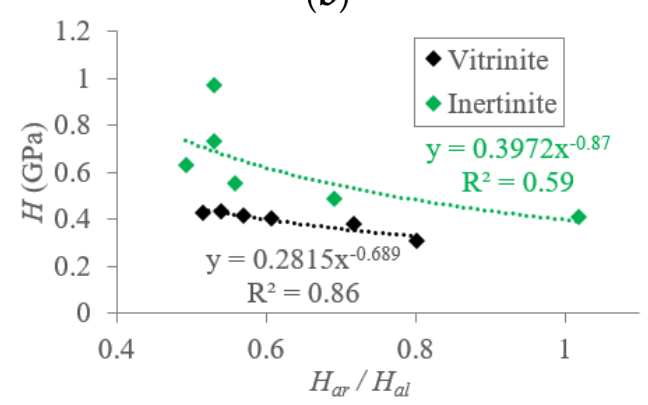

(d)

Figure 14. Relationship between FTIR parameters $\left((\mathbf{a}-\mathbf{d})\right.$ are the $\mathrm{CH}_{2} / \mathrm{CH}_{3}, \mathrm{I}, \mathrm{DOC}$, and $\mathrm{H}_{a r} / \mathrm{H}_{a l}$, respectively) and $H$. (Note: Here, $H$ is the mean value for each sample).

\subsubsection{Macromolecular Structure Effect on the Elastic Modulus (E) of TDC}

There is no correlations between the NMR parameters of inertinite and $E$ (mean value for each sample) but the NMR parameters of vitrinite show obvious relationships with $E$ (Figure 15). The $f_{a l}$ is negatively correlated with $E$ in exponential form (Figure 15a), indicating that a decrease of aliphatic carbons produces a higher elastic modulus, while the $f_{a}$ is positively correlated with $E$ in exponential form (Figure 15b), implying an increase in the $f_{a}$ suggests a higher elastic modulus, so the $f_{a} / f_{a l}$ of vitrinite is positively correlated with $E$ (Figure 15e). There is an positive correlation between $f_{a}{ }^{H}$ and $E$ (Figure 15c) and a negative correlation between $f_{a}{ }^{B}$ and $E$ (Figure 15d), suggesting that increased protonated aromatics could promote the elastic modulus, while increased aromatic bridgehead carbons could reduce the elastic modulus of the TDC. The $X_{B P}$ of vitrinite is positively correlated to $E$ (Figure 15f), suggesting that when the BSU size is larger, the elastic modulus is lower. 


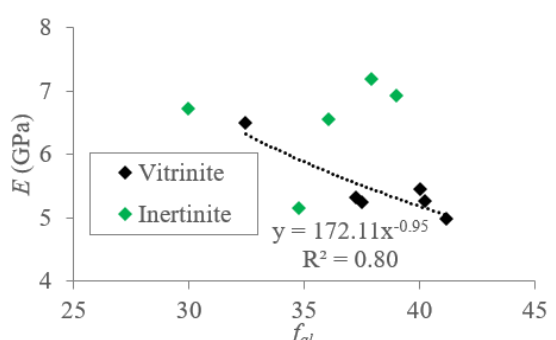

(a)

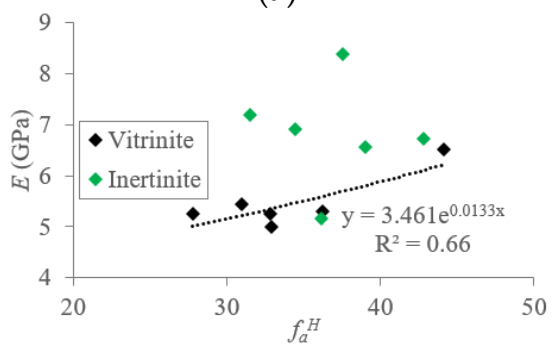

(c)

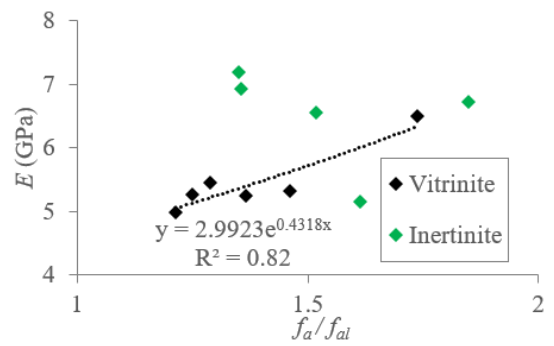

(e)

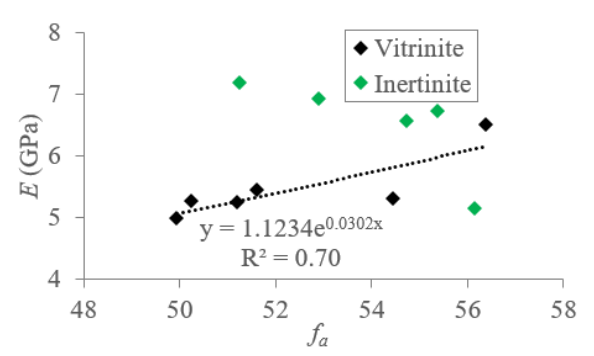

(b)

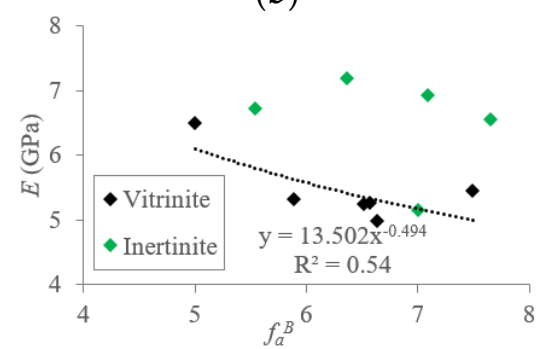

(d)

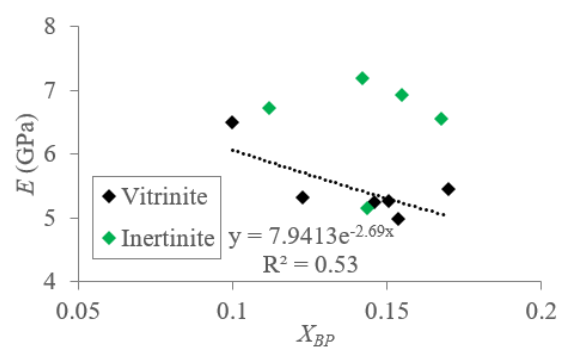

(f)

Figure 15. Relationship between NMR parameters $\left((\mathbf{a}-\mathbf{f})\right.$ are the $f_{a l}, f_{a}, f_{a}{ }^{H}, f_{a}{ }^{B}, f_{a} / f_{a l}$, and $X_{B P}$, respectively) and $E$. (Note: Here, $E$ is the mean value for each sample).

Based on FTIR results, there can be found that the all the FTIR parameters of inertinite show no correlations with elastic modulus (Figure 16), which is the same with NMR parameters, so a conclusion can be inferred that the macromolecular structure variation of inertinite cannot change the elastic regularly with the increasing deformation degree.

The macromolecular structure variation of inertinite can change the elastic modulus. (1) $\mathrm{CH}_{2} / \mathrm{CH}_{3}$ is inversely proportional to $E$ with a negative-index exponential function (Figure 16a), indicating that the detachment of aliphatic side chains increases the elastic modulus. (2) $I$ is linearly proportional to $E$ (Figure 16b), indicating that the increase in the aromatic degree increases the elastic modulus. (3) There is no obvious correlation between $D O C$ and $E$ (Figure 16c). (4) There is a linearly positive correlation between $H_{a r} / H_{a l}$ and $E$ (Figure 16d), which implies that the increase in the relative abundance of aromatics to aliphatic hydrogen increases the elastic modulus. 


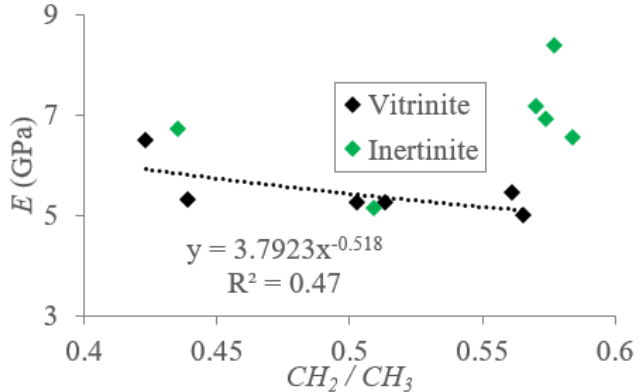

(a)

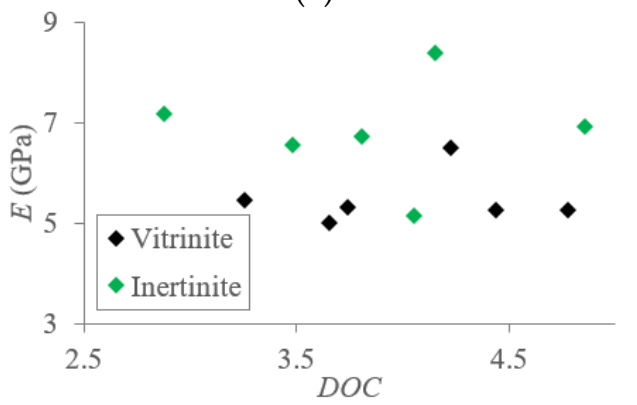

(c)

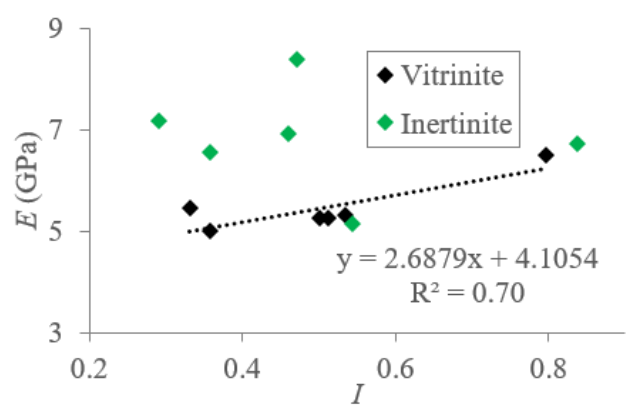

(b)

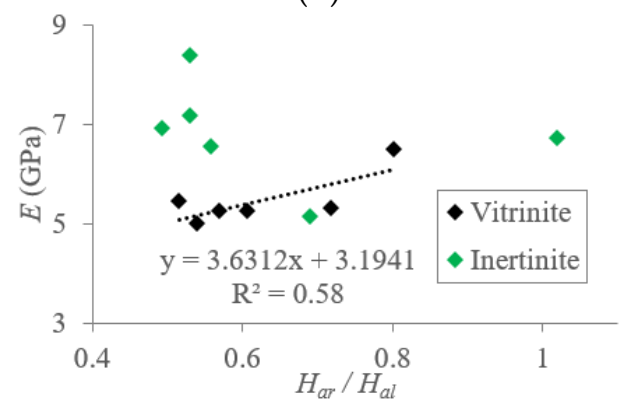

(d)

Figure 16. Relationship between FTIR parameters $\left((\mathbf{a}-\mathbf{d})\right.$ are the $\mathrm{CH}_{2} / \mathrm{CH}_{3}, \mathrm{I}, \mathrm{DOC}$, and $\mathrm{H}_{a r} / \mathrm{H}_{a l}$, respectively) and $E$. (Note: Here, $E$ is the mean value for each sample).

\subsection{Mechanisms of Mechanical Property Evolution Controlled by Macromolecular Structure}

Based on the results above, it can be concluded that the tectonic stress can change the macromolecular structure and mechanical properties of both vitrinite and inertinite. Aliphatic and aromatic carbons are the two primary components of the macromolecular structure in coal and the aliphatic side chains and benzene rings are strongly influenced by tectonic stress according to the NMR and FITR experimental results (Figures 10 and 12). The aliphatic side chains become detached, decreasing the aliphatic carbons and the benzene rings are expanded by the aromatization process, resulting in the increase in aromatic carbons. According to the conclusions obtained, the mechanism of the mechanical property evolution controlled by the macromolecular structure can be analyzed as follows.

At the nanometer scale, when the cone-shaped rigid indenter is pressed into the surface of the coal, a denser macromolecular structure is less likely to be deformed because there is not enough space surrounding the macromolecular groups in contact with the cone-shaped indenter to release the induced pressure (Figure 17a). Conversely, the compactly arranged macromolecular groups resist more strongly, resulting in high hardness. It has been confirmed that all aliphatic side chains are an critical part of macromolecules in coal [8]. As the aliphatic side chains detach, there will be many structural defects in the macromolecular structure in the TDC [26], gradually causing gaps among macromolecular groups to emerge. From unaltered coal to powdery coal, the $\mathrm{CH}_{2} / \mathrm{CH}_{3}$ values of vitrinite and inertinite decrease by $25 \%$ and $24 \%$, respectively and when the cone-shaped rigid indenter is applied, there should be more space among the macromolecular groups for the extrusion of the macromolecular groups caused by the indenter, thus reducing the hardness of the tectonic coal (Figure 17b,c). In addition, there is always interspace among the BSUs, which was confirmed by Ju et al. [1] using high-resolution transmission electron microscopy. From Samples 1 to 6, the $X_{B P}$ value of vitrinite decreased by $34.88 \%$, while that of inertinite decreased by $37.17 \%$, indicating that the distribution density of the interspace among the BSUs of the TDC will increase by more than a third from unaltered coal to powdery coal, so TDC with more interspace among the BSUs exhibit a lower hardness. 


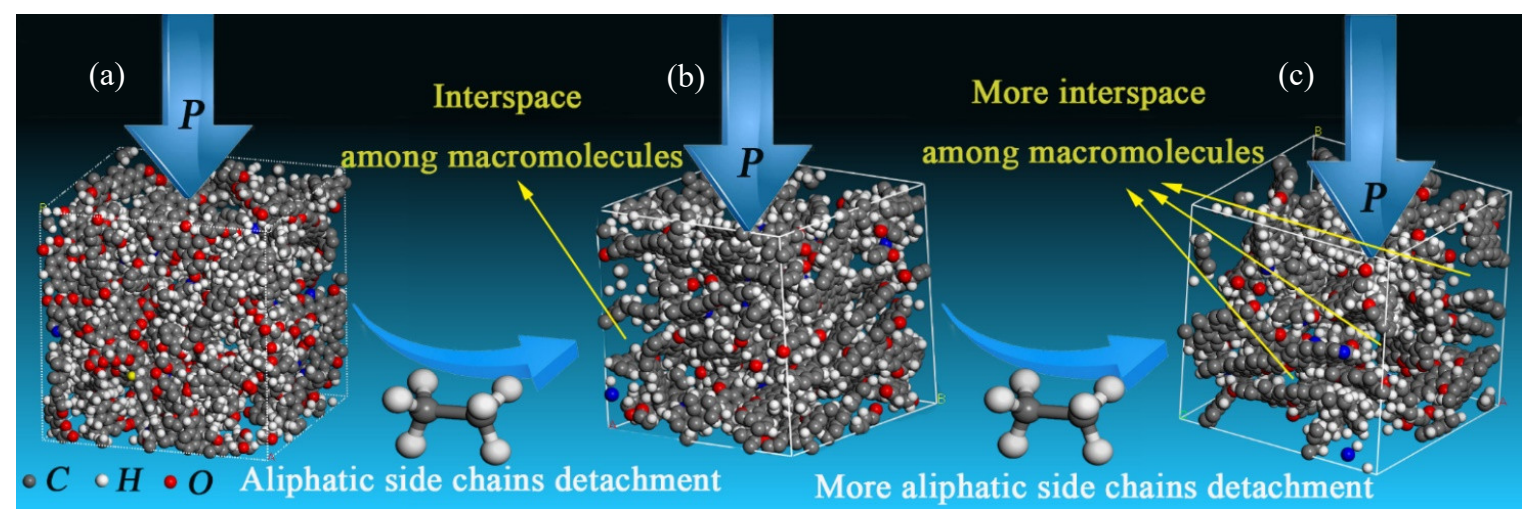

Figure 17. Sketch map of macromolecules with aliphatic side chains detaching in TDC ((a) is unalerted coal; (b) is tectonically deformed coal; (c) is tectonically deformed coal with greater deformation degree than $(\mathbf{b}))$.

The elastic modulus is a measure of the ability of an object to resist elastic deformation. From a microscopic point of view, the elastic modulus is a reflection of the bonding strength between atoms, ions or molecules and is positively related to the intermolecular forces [43]. As is well known [44], the intermolecular force is positively related to polar molecules. The polarity of a polyatomic molecule is not only related to the polarity of the chemical bond but also depends on the spatial configuration of the molecule. Therefore, the polarity of a polyatomic molecule can usually be characterized by the dipole moment [45]. According to the results of the NMR and FTIR experiments, the most prominent features of the macromolecular structural evolution of TDC are the detachment of aliphatic side chains and the increase in the relative content of aromatic molecules. Therefore, this study uses the evolution of typical molecular formulas to characterize these two evolution characteristics to explain the variation in the elastic modulus of TDC.

The dipole moment calculation can be carried out through the Visualizer module and Dmol3 module of the Materials Studio software and the calculation parameter setting adopted the method of Ge and Zhang [46]. The Visualization module was used to build the model with the parameter of: Functional: GGA, PW91; Properties: Frequency; Convergence Tolerance: Energy: $2.0 \times 10^{-5}$ Hartree; Max. force: 0.0004 Hartree; Max. displacement: $0.0005 \mathrm{~nm}$; max. step size: $0.03 \mathrm{~nm}$. The Dmo13 module was used for density-functional calculations with the parameters of: Properties: Electrostatics: Electrostatics moments; Grid interval: $0.025 \mathrm{~nm}$; Border: $0.3 \mathrm{~nm}$; Properties: Population analysis: Mulliken analysis: Atomic Charge; Hirshfeld analysis: Charge.

The calculation results are listed in Table 4. From isobutylbenzene to methylbenzene, representing the detachment of aliphatic side chains, the dipole moment value increases and the experimental values collected from Dean [47] also support the increasing trend. From naphthalene to phenanthrene, representing the increase in aromatic rings, the dipole moment value increases. From 1-Methyl naphthalene to 1-Methyl phenanthrene and from 2-Ethylnaphthalene to 2-Ethylphenanthrene, representing the increase in aromatic rings with branched aliphatic groups, the dipole moment also increases, the length of the branch is longer and the dipole moment value increases when the aromatic ring is added. Therefore, it can be inferred that the detachment of aliphatic side chains and the increase in aromatic rings may cause an increase in the molecular dipole moment in coal, thereby increasing the intermolecular forces and elastic modulus.

In addition, there are $\pi-\pi$ bonds between the unconnected benzene rings, which have been described as a type of interaction between polarized aromatic structures $[48,49]$ and are sometimes considered to contain van der Waals forces and ionic linkages [50]. According to Liu and Jiang [13], the content of $\pi-\pi$ bonds in TDC increased with a higher deformation degree, increasing the intermolecular forces and, consequently, the elastic modulus. 
Table 4. Calculation results of dipole moment for typical organic molecule.

\begin{tabular}{|c|c|c|c|c|}
\hline Name & $\begin{array}{l}\text { Molecular } \\
\text { Formula }\end{array}$ & $\begin{array}{l}\text { Molecular } \\
\text { Structure }\end{array}$ & $\begin{array}{l}\text { Calculated Dipole Moment } \\
\text { (unit: debey, D) }\end{array}$ & $\begin{array}{c}\text { Experimental Dipole } \\
\text { Moment from Dean } \\
\text { (1987) [47] }\end{array}$ \\
\hline Isobutylbenzene & $\mathrm{C}_{10} \mathrm{H}_{14}$ & & 0.33 & 0.31 \\
\hline Sec-butylbenzene & $\mathrm{C}_{10} \mathrm{H}_{14}$ & & 0.31 & 0.37 \\
\hline Ethylbenzene & $\mathrm{C}_{8} \mathrm{H}_{10}$ & & 0.37 & / \\
\hline Methylbenzene & $\mathrm{C}_{7} \mathrm{H}_{8}$ & & 0.41 & 0.45 \\
\hline Naphthalene & $\mathrm{C}_{10} \mathrm{H}_{8}$ & & 0.00 & l \\
\hline Phenanthrene & $\mathrm{C}_{14} \mathrm{H}_{10}$ & & 0.05 & l \\
\hline $\begin{array}{l}\text { 1-Methyl } \\
\text { naphthalene }\end{array}$ & $\mathrm{C}_{11} \mathrm{H}_{10}$ & & 0.53 & \\
\hline $\begin{array}{l}\text { 1-Methyl } \\
\text { phenanthrene }\end{array}$ & $\mathrm{C}_{15} \mathrm{H}_{12}$ & & $\begin{array}{l}3 \\
\stackrel{0}{0} \\
0 \\
0\end{array}$ & \\
\hline 2-Ethylnaphthalene & $\mathrm{C}_{12} \mathrm{H}_{12}$ & & 0.69 & \\
\hline 2-Ethylphenanthrene & $\mathrm{C}_{16} \mathrm{H}_{14}$ & & 2.41 & \\
\hline
\end{tabular}

\subsection{Recommendations}

It can be realized from the above conclusions that in the process of increasing deformation degree of TDCs, the changes in the mechanical properties of vitrinite and inertinite are different but the difference between the hardness and the elastic modulus of the two is getting smaller and smaller. In addition, the micro mechanical properties of vitrinite and inertinite are both controlled by the macromolecular structure. Some recommendations for future work in field of TDCs are as follows: 
(1) The tectonically deformed coal cannot be simply studied as a whole. The coal macerals should be studied separately to reveal the evolution of mechanical properties of TDCs.

(2) The coalification process of TDCs is different from that of unalerted coal and it may be more meaningful to study coalification process of TDCs from the perspective of a single coal maceral.

(3) The micro mechanical properties of vitrinite and inertinite of TDCs have obviously different evolution characteristics. As a coal reservoir, the physical properties of vitrinite and inertinite should also be different, which has important directive significances in coalbed methane exploration and the coal mine gas drainage.

\section{Conclusions}

In this study, the micromechanical properties and macromolecular structural evolution of vitrinite and inertinite in TDC with different degrees of deformation were quantified through nanoindentation experiments, NMR and FTIR and the following conclusions are obtained:

(1) The evolution of the mechanical properties of vitrinite and inertinite in TDC have been quantitatively described at the microscale. The hardness and elastic modulus of the inertinite were higher than those of the vitrinite. From unaltered coal to powdery coal, the hardness of the vitrinite and inertinite gradually decreased and the difference between the two became smaller. The elastic modulus of the vitrinite showed an increasing trend but that of the inertinite showed no obvious regularities.

(2) The inertinite did not show the characteristics of inertness under the action of tectonic stress but like the vitrinite, as the degree of deformation increased, the aliphatic side chains gradually detached and the aromatic degree increased. In addition, the size of the BSU was also reduced.

(3) For both vitrinite and inertinite, the decreases in the aliphatic carbons and the $X_{B P}$ and the increase in the ratio of $f_{a} / f_{a l}$ could reduce the hardness of the TDC. Because the detachment of aliphatic side chains could result in structural defects, there should be more interspace among the macromolecular groups for the extrusion of the macromolecular groups caused by the indentation of the subulate indenter, leading to a reduction in the hardness of the TDC.

(4) For vitrinite, the decrease in aliphatic carbons and the increase in the $f_{a} / f_{a l}$ could promote the elastic modulus because with the increasing deformation degree of the TDC, the detachment of aliphatic side chains and the addition of aromatic rings could increase the dipole moment of the macromolecules in the TDC, resulting in the increase in the intermolecular forces and elastic modulus. However, for inertinite, there is no obvious correlation between the macromolecular structures and elastic modulus.

Author Contributions: Original draft preparation, A.W.; Supervision, D.C.; Resources, Y.W.; Methodology, Z.L. All authors have read and agreed to the published version of the manuscript.

Funding: This study was financially supported by the National Natural Science Foundation of China (No. 41902170, 42072197, 41972174) and Youth Science and Technology Research Project in Natural Science Foundation of Shanxi Province (201801D221355).

Conflicts of Interest: The authors declare no conflict of interest.

\section{References}

1. Ju, Y.; Li, X. New research progress on the ultrastructure of tectonically deformed coals. Prog. Nat. Sci. 2009, 19, 1455-1466. [CrossRef]

2. Wang, A.; Cao, D.; Li, J.; Jiang, A.; Yang, C. A New Discovery on the Deformation Behavior of Shale Gas Reservoirs Affecting Pore Morphology in the Juhugeng Coal Mining Area of Qinghai Province, Northwest China. Acta Geol. Sin. 2017, 91, 1932-1933. [CrossRef]

3. Cao, D.; Wang, A.; Ning, S.; Li, H.; Guo, A.; Chen, L.; Liu, K.; Tan, J.; Zheng, Z. Coalfield structure and structural controls on coal in China. Int. J. Coal Sci. Technol. 2020, 7, 220-239. [CrossRef]

4. Wei, Y.; Cao, D.; Yuan, Y.; Zhu, X.; Zhang, X.; Yao, Z.; Zhou, J. Characteristics of Pulverized Coal during Coalbed Methane Drainage in Hancheng Block, Shaanxi Province, China. Energy Explor. Exploit. 2013, 31, 745-757. [CrossRef] 
5. Wei, Y.; Li, C.; Cao, D.; Wang, A.; Zhang, A.; Yao, Z. The effects of particle size and inorganic mineral content on fines migration in fracturing proppant during coalbed methane production. J. Pet. Sci. Eng. 2019, 182, 106355. [CrossRef]

6. Wang, A.; Wei, Y.; Yuan, Y.; Li, C.; Li, Y.; Cao, D. Coalbed methane reservoirs' pore-structure characterization of different macrolithotypes in the southern Junggar Basin of Northwest China. Mar. Pet. Geol. 2017, 86, 675-688. [CrossRef]

7. Wang, A.; Li, J.; Wei, Y.; Yang, C.; Nie, J.; Cao, D. Gas migration for terrestrial gas hydrates in the Juhugeng mining area of Muli basin, Qilian Mountains, Northwest China. Energy Explor. Exploit. 2020, 38, 989-1013. [CrossRef]

8. Cao, D.; Li, X.; Zhang, S. Influence of tectonic stress on coalification: Stress degradation mechanism and stress polycondensation mechanism. Sci. China Ser. D: Earth Sci. 2007, 50, 43-54. [CrossRef]

9. Wang, X.; Chen, T.; Xu, H. Thickness Distribution Prediction for Tectonically Deformed Coal with a Deep Belief Network: A Case Study. Energies 2020, 13, 1169. [CrossRef]

10. Lu, J.; Wang, Y.; Chen, J. Detection of Tectonically Deformed Coal Using Model-Based Joint Inversion of Multi-Component Seismic Data. Energies 2018, 11, 829. [CrossRef]

11. Pan, J.; Zhu, H.; Hou, Q.; Wang, H.; Wang, S. Macromolecular and pore structures of Chinese tectonically deformed coal studied by atomic force microscopy. Fuel 2015, 139, 94-101. [CrossRef]

12. Chen, Q.; Jing, J.; Liu, J.; Long, J.; Zhang, S. Productivity Evaluation of Coalbed Methane Well with Geophysical Logging-Derived Tectonically Deformed Coal. Energies 2019, 12, 3459. [CrossRef]

13. Liu, H.; Jiang, B. Stress response of noncovalent bonds in molecular networks of tectonically deformed coals. Fuel 2019, 255, 115785. [CrossRef]

14. Cao, D.Y.; Zhang, S.R.; Ren, D.Y. The influence of structural deformation on coalification: A case study of carboniferous coal measures in the northern foothills of the Dabie orogenic belt. Geological Review 2002, 48, 313-317.

15. Godyń, K.; Kožušníková, A. Microhardness of Coal from Near-Fault Zones in Coal Seams Threatened with Gas-Geodynamic Phenomena, Upper Silesian Coal Basin, Poland. Energies 2019, 12, 1756. [CrossRef]

16. Li, W.; Liu, H.; Song, X. Multifractal analysis of $\mathrm{Hg}$ pore size distributions of tectonically deformed coals. Int. J. Coal Geol. 2015, 138-152. [CrossRef]

17. Stach, E.; Mackowsky, M.-T.H.; Techmuller, M. Stach's textbook of coal petrology, 3rd ed.; Gebrüder Borntraeger: Berlin, Germany, 1982; pp. 66-107.

18. Wang, A.; Cao, D.; Wei, Y.; Nie, J.; Qin, R. Comparison of nanopore evolution in vitrinite and inertinite in coalbed methane reservoirs during coalification. J. Nat. Gas Sci. Eng. 2020, 78, 103289. [CrossRef]

19. Qin, R.; Wang, A.; Cao, D.; Wei, Y.; Ding, L.; Li, J. Effect of peat mire evolution on pore structure characteristics in thick coal seam: Examples from Xishanyao Formation (Middle Jurassic), Yili Basin, China. Energy Explor. Exploit. 2020, 38, 1484-1514. [CrossRef]

20. Pan, J.; Meng, Z.; Hou, Q.; Ju, Y.; Cao, Y. Coal strength and Young's modulus related to coal rank, compressional velocity and maceral composition. J. Struct. Geol. 2013, 54, 129-135. [CrossRef]

21. Hou, C.; Jiang, B.; Liu, H.; Song, Y.; Xu, S. The differences of nanoscale mechanical properties among coal maceral groups. J. Nat. Gas Sci. Eng. 2020, 80, 103394. [CrossRef]

22. Kožušníková, A. Determination of microhardness and elastic modulus of coal components by using indentation method. Geolines 2009, 22, 40-43.

23. Godyń, K.; Dutka, B.; Chuchro, M.; Młynarczuk, M. Synergy of Parameters Determining the Optimal Properties of Coal as a Natural Sorbent. Energies 2020, 13, 1967. [CrossRef]

24. Fender, T.; Rouainia, M.; Van Der Land, C.; Jones, D.M.; Mastalerz, M.; Hennissen, J.A.; Graham, S.P.; Wagner, T. Geomechanical properties of coal macerals; measurements applicable to modelling swelling of coal seams during CO2 sequestration. Int. J. Coal Geol. 2020, 228, 103528. [CrossRef]

25. Ju, Y.; Jiang, B.; Hou, Q.-L.; Wang, G.-L. [FTIR spectroscopic study on the stress effect of compositions of macromolecular structure in tectonically deformed coals]. Guang Pu Xue Yu Guang Pu Fen Xi 2005, 25, 1216-1220.

26. Song, Y.; Jiang, B.; Qu, M. Macromolecular evolution and structural defects in tectonically deformed coals. Fuel 2019, 236, 1432-1445. [CrossRef] 
27. Cao, D.Y.; Zhan, W.F.; Zhang, J.; Yang, S.C.; Zhang, L.S.; Fan, H.P.; Huang, P.; Qiao, J.; Liu, D.M.; Chang, M.H. Neotectonic character of Handan-Fengfeng mining area and its significance for coal resource exploitation. J. China Coal Soc. 2007, 32, 141-145.

28. Lv, D.W.; Lu, C.; Wen, Z.; Song, H.; Yin, S. Coal-bed methane geology of the No. 2 coal seam in Fengfeng Coalfield, North China. Arab. J. Geosci. 2019, 12, 529. [CrossRef]

29. Bao, Y.; Wang, W.; Zhou, Y. Investigation of the relationship between elastic modulus and hardness based on depth-sensing indentation measurements. Acta Mater. 2004, 52, 5397-5404. [CrossRef]

30. Sun, C.L.; Li, G.C.; Elgharib, G.M.; Xu, J.H.; Rong, H.Y. Experimental investigation on the mechanical properties of crushed coal samples based on the nanoindentation technique. J. China Coal Soc. 2020. [CrossRef]

31. Oliver, W.; Pharr, G. An improved technique for determining hardness and elastic modulus using load and displacement sensing indentation experiments. J. Mater. Res. 1992, 7, 1564-1583. [CrossRef]

32. Painter, P.; Starsinic, M.; Coleman, M. Determination of functional groups in coal by Fourier transform interferometry. Fourier Transform. Infrared Spectra 1985, 169-241. [CrossRef]

33. Ibarra, J.; Muñoz, E.; Moliner, R. FTIR study of the evolution of coal structure during the coalification process. Org. Geochem. 1996, 24, 725-735. [CrossRef]

34. Ibarra, J.V.; Munoz, E.R.; Bonet, A.J. FT-IR investigation on char formation during the early stages of coal pyrolysis. Fuel 1994, 73, 918-924. [CrossRef]

35. Guo, Y.; Bustin, R. Micro-FTIR spectroscopy of liptinite macerals in coal. Int. J. Coal Geol. 1998, 36, $259-275$. [CrossRef]

36. Dutta, S.; Hartkopf-Fröder, C.; Witte, K.; Brocke, R.; Mann, U. Molecular characterization of fossil palynomorphs by transmission micro-FTIR spectroscopy: Implications for hydrocarbon source evaluation. Int. J. Coal Geol. 2013, 115, 13-23. [CrossRef]

37. Song, Y.; Jiang, B.; Mathews, J.P.; Yan, G.; Li, F. Structural transformations and hydrocarbon generation of low-rank coal (vitrinite) during slow heating pyrolysis. Fuel Process. Technol. 2017, 167, 535-544. [CrossRef]

38. Li, W.; Zhu, Y. Structural Characteristics of Coal Vitrinite during Pyrolysis. Energy Fuels 2014, 28, 3645-3654. [CrossRef]

39. Liu, Y.; Zhu, Y.; Chen, S. Effects of chemical composition, disorder degree and crystallite structure of coal macromolecule on nanopores $(0.4-150 \mathrm{~nm})$ in different rank naturally-matured coals. Fuel 2019, 242, 553-561. [CrossRef]

40. Suggate, R.; Dickinson, W. Carbon NMR of coals: The effects of coal type and rank. Int. J. Coal Geol. 2004, 57, 1-22. [CrossRef]

41. Erdenetsogt, B.-O.; Lee, I.; Lee, S.K.; Ko, Y.-J.; Bat-Erdene, D. Solid-state C-13 CP/MAS NMR study of Baganuur coal, Mongolia: Oxygen-loss during coalification from lignite to subbituminous rank. Int. J. Coal Geol. 2010, 82, 37-44. [CrossRef]

42. Malumbazo, N.; Wagner, N.; Bunt, J.; Van Niekerk, D.; Assumption, H. Structural analysis of chars generated from South African inertinite coals in a pipe-reactor combustion unit. Fuel Process. Technol. 2011, 92, 743-749. [CrossRef]

43. Dong, J.; Cheng, Y.; Hu, B.; Hao, C.; Tu, Q.; Liu, Z.-D. Experimental study of the mechanical properties of intact and tectonic coal via compression of a single particle. Powder Technol. 2018, 325, 412-419. [CrossRef]

44. Liu, F.; Yang, H.; Yang, M.; Wu, J.; Yang, S.; Yu, D.; Wu, X.; Wang, J.; Gates, I.D.; Wang, J. Effects of molecular polarity on the adsorption and desorption behavior of asphaltene model compounds on silica surfaces. Fuel 2021, 284, 118990. [CrossRef]

45. Al-Malah, K.I. Aqueous solubility of a simple (single-carbon) organic molecule as a function of its size \& dipole moment. J. Mol. Model. 2011, 17, 1029-1034. [CrossRef] [PubMed]

46. Ge, T.; Zhang, M.X. Dielectric properties of the model compounds of thiophene sulfur in coals and its relation to molecular polarity. J. China Univ. Min. Technol. 2016, 45, 1245-1250.

47. Dean, J.A. Hand Book of Organic Chemistry; McGraw-Hill: New York, NY, USA, 1987; pp. 450-500.

48. Nishioka, M.; Larsen, J.W. Association of aromatic structures in coals. Energy Fuels 1990, 4, 100-106. [CrossRef]

49. You, C.-Y.; Fan, X.; Zheng, A.-L.; Wei, X.-Y.; Zhao, Y.-P.; Cao, J.-P.; Zhao, W.; Zhou, C.-C.; Zhu, J.-L.; Chen, L.; et al. Molecular characteristics of a Chinese coal analyzed using mass spectrometry with various ionization modes. Fuel 2015, 155, 122-127. [CrossRef] 
50. Iino, M. Network structure of coals and association behavior of coal-derived materials. Fuel Process. Technol. 2000, 62, 89-101. [CrossRef]

Publisher's Note: MDPI stays neutral with regard to jurisdictional claims in published maps and institutional affiliations.

(C) 2020 by the authors. Licensee MDPI, Basel, Switzerland. This article is an open access article distributed under the terms and conditions of the Creative Commons Attribution (CC BY) license (http://creativecommons.org/licenses/by/4.0/). 